\title{
NUEVAS FORMAS DE RESISTENCIA TRANSNACIONAL: LA LUCHA AWÁ, 2009-2014*
}

\section{NEW WAYS OF TRANSNATIONAL RESISTANCE: THE AWÁ STRUGGLE, 2009-2014}

\author{
Danna Carolina Aguilar-Gómez** \\ JEFFERSON JosÉ CRUZ-MEdINA*** \\ JuAn David SÁNChEZ-VARGaS**** \\ Sergio Esteban Torres-Chaves*****
}

Fecha de recepción: 28 de octubre de 2016

\section{PARA CITAR ESTE ARTÍ́cUlo/To CITE THIS ARTICLE}

Aguilar-Gómez, Danna Carolina; Cruz-Medina, Jefferson José; SánchezVargas, Juan David \& Torres-Chaves, Sergio Esteban, Nuevas formas de resistencia transnacional: la lucha Awá, 2009-2014, 29 International Law, Revista Colombiana de Derecho Internacional, 9-56 (2016). http://dx.doi. org/10.11144/ Javeriana.il 14-29.nfrt

doi:10.11144/Javeriana.i114-29.nfrt

\footnotetext{
* $\quad$ Este artículo fue presentado por primera vez el 9 de noviembre de 2015 en la Convocatoria 074 de 2014 para la selección de Semilleros de Investigación I, al Instituto Unidad de Investigaciones Jurídico-Sociales Gerardo Molina (UNIJUS), de la Facultad de Derecho, Ciencias Políticas y Sociales, de la Universidad Nacional de Colombia. Sin embargo, se realizaron modificaciones sustanciales para la publicación en International Law, Revista Colombiana de Derecho Internacional.

** Politóloga de la Universidad Nacional de Colombia, sede Bogotá. Contacto: dcaguilarg@ unal.edu.co

*** Politólogo de la Universidad Nacional de Colombia, sede Bogotá. Contacto: jejcruzme@ unal.edu.co

**** Politólogo de la Universidad Nacional de Colombia, sede Bogotá. Contacto: judsanchezva@ unal.edu.co

***** Politólogo de la Universidad Nacional de Colombia, sede Bogotá. Contacto: setorresc@unal. edu.co
} 


\section{RESUMEN}

El presente texto pretende comprender cómo se ha desarrollado el proceso de resistencia y lucha del pueblo indígena Awá en el plano internacional, frente a las problemáticas ligadas con el conflicto armado interno colombiano en el período comprendido entre 2009 y 2014. Para alcanzar este propósito fue indispensable la realización de un trabajo de campo con la comunidad Awá en el corregimiento de Llorente, San Andrés de Tumaco (departamento de Nariño), en el que se pusieron en práctica técnicas de recolección de la información como entrevistas grupales a líderes de la comunidad que aportaron a la construcción de este escrito. De esta manera, el estudio evidencia que la lucha del pueblo indígena Awá por la defensa de sus derechos ha estado mediada por la creación de redes transnacionales de defensa y la instrumentalización subalterna del derecho internacional en un contexto en el que la estrategia política de internalización de la causa indígena ha tomado vuelo.

Palabras claves: pueblo indígena Awá; redes transnacionales de defensa; instrumentalización subalterna del derecho internacional; movimiento indígena. 


\begin{abstract}
The present paper attempts to understand the process of resistance and struggle of the Colombian indigenous people Awá at the international level to confront the problems related to the Colombian internal armed conflict in the period between 2009 and 2014. In order to reach this goal, fieldwork with the Awá community in the Llorente district of San Andrés de Tumaco (Nariño Department) was indispensable, in which information gathering techniques were used as group interviews with leaders of the community, who contributed to the construction of this article. In this way, the study shows that the struggle for the defense of the Awá indigenous peoples' rights has been mediated by the creation of transnational defense networks and the subordinate instrumentalization of international law, in a context where the political strategy of internalization of the indigenous cause has taken off.
\end{abstract}

Keywords: Awá Indigenous People; Transnational Defense Networks; Subaltern Instrumentalization of International Law; Indigenous Movement

SUMARIO

Introducción.- I. Aproximaciones CONCEPTUALes.- II. Contra la vida Awá.III. En DEFENSA DE LA VIDA AwÁ.- A. En el plano nacional.- 1. El pueblo Awá reivindica sus derechos.- $B$. La lucha Awá en el plano internacional. 1. Para tejer vínculos más allá de las fronteras nacionales. 2. Denuncia y resistencia en el derecho internacional. 3. La gira por Europa: transnacionalización de la causa Awá.- Conclusiones.- Bibliografía. 
INTRODUCCIÓN

El pueblo indígena Awá o los hijos de la montaña, como se autodenominan, cuentan con una población de cerca de $35.000^{1}$ indígenas, ubicados en la zona fronteriza entre Colombia y Ecuador - en los departamentos de Nariño y Putumayo - (mapa 1). En los últimos años se han visto crecientemente azotados por diferentes problemas relacionados con el conflicto armado interno colombiano. Entre ellos están las fumigaciones con glifosato contra los cultivos de uso ilícito y sus respectivas consecuencias para la salud humana; la contaminación de ríos por cuenta del derrame de petróleo y desechos de minería; así como el sostenimiento de hostilidades entre actores armados legales e ilegales. Esto los ha convertido en víctimas de asesinatos selectivos, masacres, violaciones y abusos sexuales, desplazamientos forzados y confinamientos territoriales, en especial en razón de las minas antipersona, lo que constituye una amenaza para su supervivencia física, psicológica, cultural y espiritual.

1 Algunos informes del Colectivo de Abogados José Alvear Restrepo señalan que el "genocidio lo ha reducido [al Pueblo Indígena Awá] a solo unos 27.000 habitantes". Colectivo de Abogados José Alvear Restrepo, Colectivo Maloka, Se presentó informe en Barcelona que denuncia el exterminio del pueblo indígena Awá de Colombia. Disponible en: http://www.colectivodeabogados.org/noticias/noticias-nacionales/Se-presento-informe-en-Barcelona 


\section{MAPA 1}
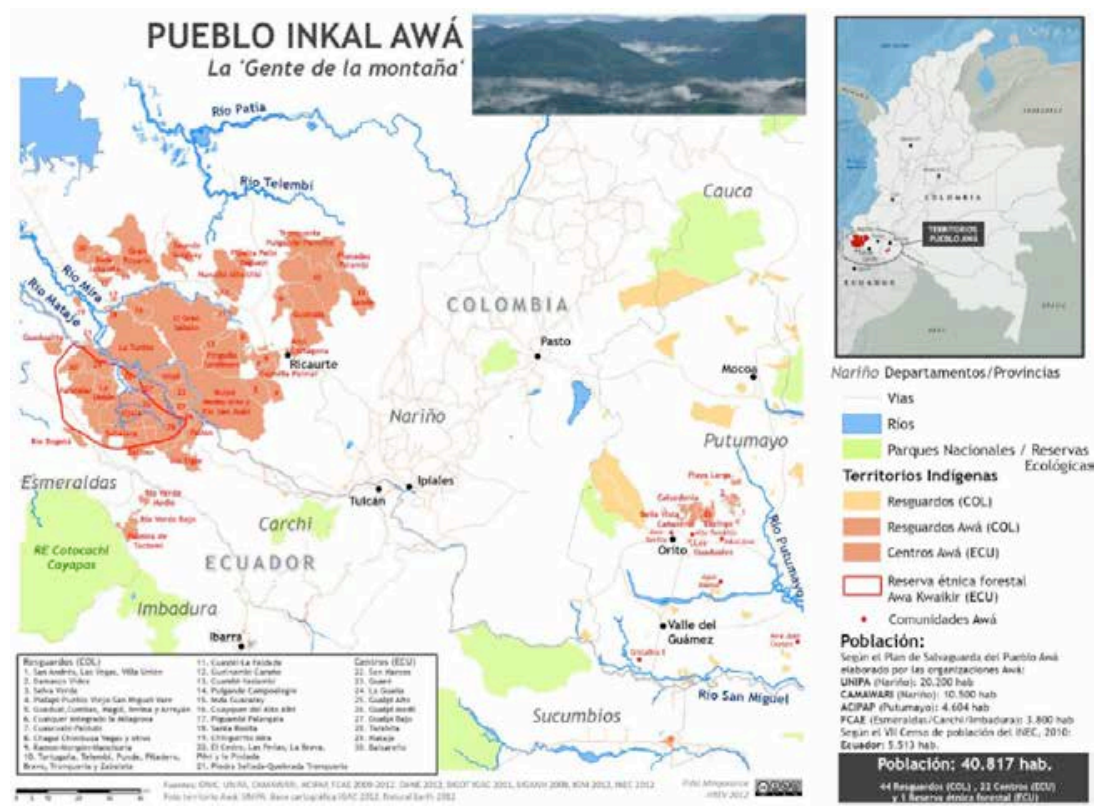

Mapa 1. Georreferenciación del territorio indígena del pueblo Inkal Awá.

Fuente: Unidad Indígena del Pueblo Awá, UNIPA (2012). En Angélica Franco-Gamboa, Reconstrucciones de la cotidianidad en el pueblo indígena Awa: espacios minados, tiempo natural y sobrenatural, 59 (Tesis doctoral en Antropología, Universidad Nacional de Colombia, Bogotá, Colombia, 2015). Disponible en: http://www.bdigital.unal.edu.co/49616/

El punto álgido de esta problemática se presentó en 2009, cuando las cifras de violaciones de derechos humanos se incrementaron drásticamente con tres masacres, que registraron cuando menos 41 asesinatos y posteriores desplazamientos forzados de algunos miembros de la comunidad ${ }^{2}$. Otro dato revelador de la magnitud de esta problemática es que más de la mitad de las víctimas indígenas de homicidio en todo el país ese año pertenecía al Pueblo Awá3. Tras estos acontecimientos,

2 Observatorio por los Derechos y la Supervivencia de los Pueblos Indígenas de Colombia, OPIC, SOS a la ONU y la Corte Penal Internacional sobre el exterminio del pueblo Awá de Colombia (Barcelona, 2012). Disponible en: http://viva.org.co/cajavirtual/svc0307/pdfs/articulo308_307. pdf

3 Amnistía Internacional, La lucha por la supervivencia y la dignidad. Abusos contra los derechos 
en la búsqueda de soluciones a su problemática, el pueblo Awá demandó amparo en el derecho interno y encontró respuestas formales que no tuvieron efectos reales en la práctica: la Corte Constitucional ordenó al gobierno nacional en dos ocasiones tomar medidas eficaces para solventar la situación del pueblo Awá o por lo menos suspender las violaciones de derechos humanos. Sin embargo, el gobierno colombiano continuó haciendo caso omiso. En este marco, hacia 2011, se dio inicio al proceso de lucha en el plano internacional, de tal manera que la Comisión Interamericana de Derechos Humanos (CIDH) profirió medidas cautelares para la protección del pueblo Awá, con énfasis en el desminado humanitario. Pese a que la Corte Constitucional dictaminó el cumplimiento de tales medidas, la problemática del pueblo indígena persistió.

En consecuencia, en la búsqueda de soluciones pertinentes, los Awá han optado por visibilizar su problemática como un asunto de interés global, por medio de dos estrategias: las redes transnacionales de defensa y la instrumentalización subalterna del derecho internacional. Esto gracias a la ayuda y colaboración tanto de Organizaciones No Gubernamentales (ONG), con la presentación del informe desarrollado por el Observatorio por los Derechos y la Supervivencia de los Pueblos Indígenas en Colombia de Cataluña, PIC (actualmente Observatorio ADPI), ante la CIDH; como de organizaciones gubernamentales, como la Organización de las Naciones Unidas (ONU), con la visita del Foro Permanente para las Cuestiones Indígenas al pueblo Awá en 2010 y a principios de 2011, que tuvo como resultado múltiples recomendaciones al Estado colombiano para la protección de los Awá4.

humanos de los pueblos indigenas en Colombia, 2-12 (Editorial de Amnistía Internacional, EDAI, Madrid, 2010). Disponible en: http://amnistiainternacional.org/publicaciones/97colombia-la-lucha-por-la-supervivencia-y-la-dignidad-abusos-contra-los-derechos-humanosde-los-pueblos-indigenas.html

4 Observatorio por la Autonomía y los Derechos de los Pueblos Indígenas en Colombia, Observatorio ADPI, El Pueblo Awá solicita a la Oficina del Relator de Pueblos Indígenas de la ONU una visita a su territorio (13 de marzo de 2014). Disponible en: http://observatorioadpi. org/content/el-pueblo-awa-solicita-la-oficina-del-relator-de-pueblos-indigenas-de-la-onu-unavisita-su-t 
Lo anterior cobra sentido si se enmarca en el contexto de la transnacionalización de los movimientos sociales, proceso que, como lo plantea Sidney Tarrow, encuentra causa en el acelerado desarrollo de la telemática y la globalización económica. Estas transformaciones han llevado a la conformación de una nutrida red de organizaciones y movimientos que escapan de sus fronteras nacionales y que mantienen una férrea relación con el entramado de organizaciones internacionales ${ }^{5}$. De esta forma, el Derecho Internacional, como entramado de principios y normas que pretenden regir la organización y el funcionamiento del orden internacional, también ha estado sometido a estos procesos, entre los cuales cabe destacar su instrumentalización por parte de los movimientos sociales en función del contrapoder, para presionar la formalización de sus reivindicaciones tanto en el plano internacional como en el nacional y convertirlo así en un mecanismo de resistencia en el contexto de desigualdad creciente. En este sentido, es válido cuestionarse, ¿cómo el pueblo indígena Awá ha buscado dar solución a sus problemáticas en el plano internacional en el período comprendido entre 2009 y 2014 ?

A propósito, sostenemos que el proceso de resistencia y lucha del Pueblo Indígena Awá en el plano internacional se ha desarrollado por medio de redes transnacionales de defensa y de la instrumentalización subalterna del derecho internacional. En primer lugar, este proceso ha consistido en la búsqueda de vínculos y alianzas con organizaciones internacionales, así como en la realización de lobby en instancias internacionales, en pro de visibilizar globalmente las múltiples problemáticas que aquejan al pueblo y lograr solidaridad hacia las mismas. En segundo lugar, se ha generado un aprovechamiento de los canales del Derecho Internacional para presionar la garantía efectiva de sus derechos en el plano nacional, con el fin de al-

5 Mónica N. Acosta-García, Aproximación al estudio de redes transnacionales de defensa y prácticas de Derechos Humanos: análisis de la incidencia de la ONIC en la Organización de las Naciones Unidas. El caso del desplazamiento forzado de los Pueblos Indigenas Emberas, en Identidades políticas porosas: estudios sobre las reivindicaciones nacionales y transnacionales, 57-130, 67 (Ana Rodríguez, Ángela del Pilar Santamaría, Édgar Naranjo, Mónica Acosta \& Pedro Rojas, Editorial Universidad del Rosario, Bogotá, 2012). 
canzar mayor legitimación en sus demandas. La convergencia de estas dos estrategias ha tenido como fin una formalización de sus reivindicaciones en el derecho internacional y nacional que suponga una real solución a sus problemas.

Para defender lo anterior, consideramos imprescindible estudiar los efectos concretos de la lucha internacional de los Awá en la consecución de sus reivindicaciones, pues de esta manera evitamos caer en el error de muchos otros autores - examinados a fondo más adelante- que, con la pretensión de evaluar la internacionalización de la cuestión indígena, olvidan evaluar los impactos concretos de estas luchas en el ámbito interno.

De esta manera, el presente texto pretende realizar un recorrido por el proceso de resistencia y lucha del pueblo indígena Awá en el plano internacional. En primer lugar, se sitúan los abordajes dominantes del proceso de internacionalización de la cuestión indígena, para acotar un marco analítico y conceptual. Enseguida, se revisa la vida organizativa del pueblo Awá, para dar cuenta de su creciente complejización. En tercer lugar, se profundiza en los problemas que azotan a este pueblo indígena, para abordar el proceso reivindicativo del pueblo en los marcos jurídico-institucionales nacionales. Posteriormente, se analizará la movilización social del pueblo Awá más allá de las fronteras colombianas mediante la instrumentalización subalterna del derecho internacional y de la creación de redes transnacionales de defensa. Finalmente, se presentarán las conclusiones. 


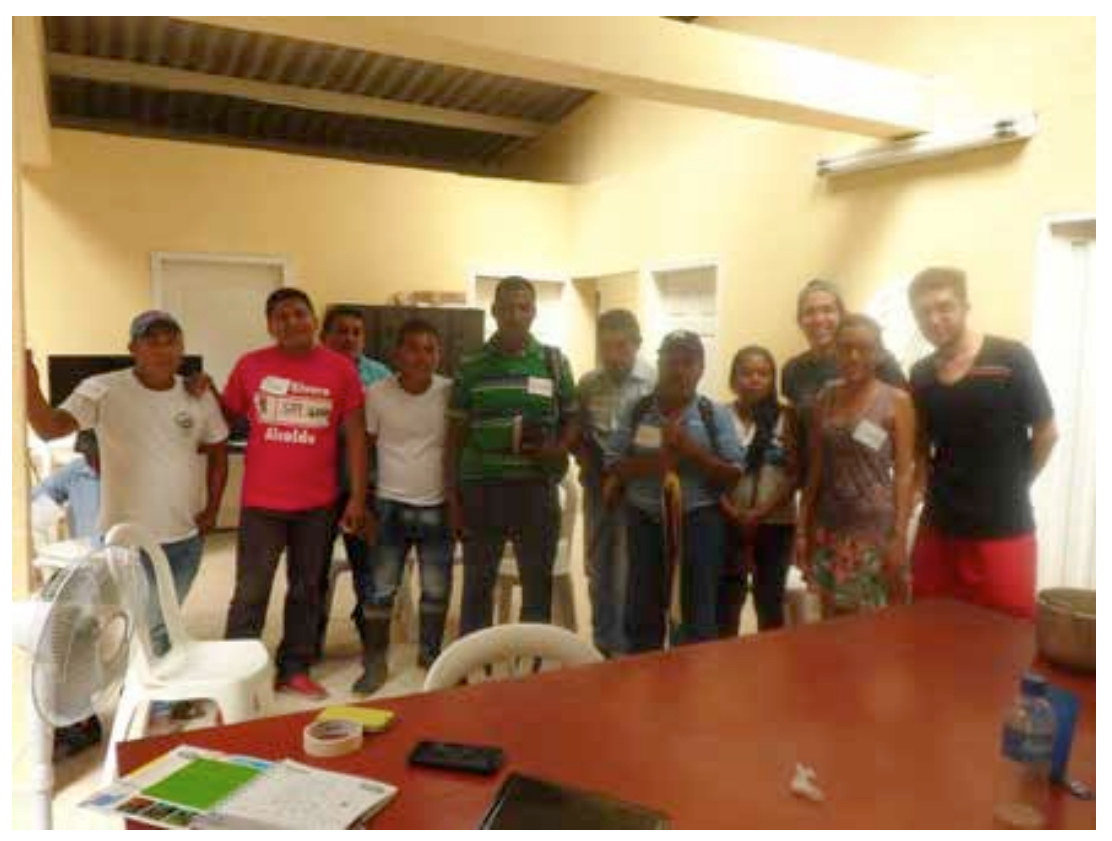

Foto 1. Taller de socialización con líderes del pueblo indígena Awá, realizado en el trabajo de campo. Llorente, municipio de San Andrés de Tumaco, 2014.

\section{APROXIMACIONES CONCEPTUALES}

En la década de los noventa, el movimiento indígena en América Latina hizo eclosión a escala global, gracias a la internacionalización de la cuestión indígena, producto de la creciente preocupación mundial por la conservación de la biodiversidad, el medio ambiente y la diversidad cultural ${ }^{6}$. Fenómenos como las medidas de ajuste estructural de corte neoliberal, la creciente explotación de recursos naturales en territorios ancestrales por empresas transnacionales, la adopción de políticas indigenistas por parte de algunos gobiernos, la declaración del Convenio 169 sobre Pueblos Indígenas y Tribales en Países Independientes por parte de la Organización Internacional del Trabajo (OIT),

6 Daniel Ricardo Peñaranda-Supelano, Organizaciones indígenas y participación política en Colombia. El acceso a los espacios de representación 1990-2002, 17 (La Carreta Editores, Instituto de Estudios Políticos y Relaciones Internacionales, IEPRI, Universidad Nacional de Colombia, Medellín, 2009). 
principalmente, pusieron al movimiento indígena en el centro de la palestra. En este marco, los estudios sobre el movimiento indígena empezaron a centrarse en cuestiones como su relación con ONG nacionales e internacionales, con otros movimientos indígenas del globo y con movimientos sociales, como el ambientalista. En el caso colombiano, los estudios sobre el movimiento indígena se han enfocado en la conquista del Estado multicultural fruto de la Constitución de 1991, la jurisdicción especial indígena, la consulta previa y la autonomía territorial.

Dado que este trabajo pretende analizar el proceso de internacionalización de la cuestión indígena, es pertinente pasar revista a la literatura sobre el tema. Así en primer lugar, repasamos el trabajo pionero de Ángela Santamaría, quien en su libro las Redes transnacionales y la emergencia de la diplomacia indígena: un estudio transnacional a partir del caso colombiano, se traza como objeto de estudio las prácticas jurídicas y políticas de la producción transnacional del derecho de los pueblos indígenas, a partir de la experiencia de sus agentes sociales en la especificidad del caso colombiano. Este estudio es innovador, dado que trasciende de la mirada imperante que se centra en la presentación del corpus jurídico pluralista conquistado por el movimiento indígena, a una mirada centrada en las prácticas de los agentes sociales, sus recursos y estrategias.

Desde su particular perspectiva teórica, la autora estudia la internacionalización del conocimiento experto sobre los pueblos indígenas e intenta "comprender el tipo de relaciones de dominación que se establecen entre los distintos agentes, como prácticas estructuradoras de este universo social"7. En tal sentido, propone una redefinición sociológica del análisis de la movilización política y su profesionalización por medio de los procesos de formalización jurídica y de los repertorios de acción de los agentes especializados. Conduciendo a una perspectiva crítica del derecho, que pone de relieve las relaciones

7 Ángela del Pilar Santamaría-Chavarro, Redes transnacionales y emergencia de la diplomacia indigena: un estudio transnacional a partir del caso colombiano, 15 (Editorial Universidad del Rosario, Bogotá, Colombia, 2008). 
de dominación y violencia simbólica que esta encierra y, por tanto, mina las visiones idealistas del derecho que ensalzan su potencial emancipatorio.

Pese a estos importantes aportes, la investigación de Santamaría adolece de limitaciones. Al centrarse en el estudio del proceso de producción del derecho de los pueblos indígenas, la investigación descuida el análisis de los efectos materiales de este proceso en la cotidianidad de los mismos indígenas. Así, aunque pretende realizar un análisis desde la experiencia de los agentes sociales, soslaya a los que debieran ser sus protagonistas: las bases del movimiento indígena.

Otra perspectiva de gran importancia en esta materia, enfocada en América Latina, viene de la mano de Alison Brysk. Esta politóloga estadounidense sostiene que el éxito del movimiento indígena no puede explicarse únicamente por la capacidad de las organizaciones indígenas para generar acuerdos políticos en torno a sus demandas en cada país, sino por la capacidad de las políticas de identidad de movilizar y articular políticamente a los sujetos indígenas locales, al tiempo que se crean redes transnacionales de apoyo en el contexto de la globalización. En este sentido, la autora parte de la identidad indígena como un proceso de construcción que consiste en la recreación de una identidad indígena histórica y local en los años 90, que posteriormente transmutó en una identidad que se difunde y se reproduce a sí misma, pero a escala internacional, hasta erigirse en una identidad transnacional.

Para argumentar su hipótesis, la autora estudia las relaciones internacionales de las comunidades indígenas de Ecuador, Brasil, México, Nicaragua y Bolivia desde los años 60 hasta los 90 e intenta demostrar la aparición del movimiento indígena transnacional. Tal idea es reforzada por el concepto de redes de movimientos transnacionales, que han impulsado y dado aliento a determinados modos organizativos, lo que ha abierto espacio para el movimiento indígena y sus reivindicaciones en cuanto a organismos y normas globales se refiere. Esto, a su vez, tiene como consecuencia que algunos gobiernos hayan creado "los 
espacios políticos específicos - locales y regionales-, para los pueblos indígenas que están bajo su dominio".

Valga decir entonces que para la autora la globalización tiene una connotación doble. Por un lado, esta ha traído para los pueblos indígenas nuevas amenazas, debido a "la presencia militar, a la llegada de empresas codiciosas de recursos y a la implantación de nuevas formas de vida y de consumo"9. Por el otro lado, la transnacionalización del Estado ha significado para el movimiento indígena mayores oportunidades políticas, en rubros como la participación en sus instituciones, estrategias de cooperación y una capacidad sin precedentes de formación de sus miembros.

Ahora bien, la investigación de Boaventura de Sousa-Santos y César Rodríguez-Garavito también tiene un sentido complementario para nuestro análisis en la medida en que estos autores se proponen abordar "el papel del derecho en la globalización contrahegemónica y los retos que esta última plantea a la teoría y la práctica jurídicas"10. En este sentido, su contribución específica radica en su perspectiva particular "desde abajo" sobre el derecho y la globalización que abordan e ilustran empíricamen$\mathrm{te}^{11}$. En pro de esto, los autores proponen la categoría analítica de legalidad cosmopolita subalterna.

La propuesta de estos dos autores responde a las falencias de dos enfoques que han tratado este tema. Por una parte, a la obra académica de la "gobernanza global", que estudia la transfor-

8 Alison Brysk, Globalización y pueblos indígenas: el rol de la sociedad civil internacional en el siglo XXI, en Pueblos indígenas y política en América Latina: el reconocimiento de sus derechos y el impacto de sus demandas a inicios del siglo XX, 17-30, 22 (Salvador Martí i Puig, coord., Fundación CIDOB, Barcelona, 2007). Disponible en: http://www.cidob.org/es/ publicaciones/serie_de_publicacion/interrogar_la_actualidad/pueblos_indigenas_y_politica_en_america_latina

9 Ibid., p. 18.

10 Boaventura de Sousa-Santos \& César A. Rodríguez-Garavito, El derecho, la política y lo subalterno en la globalización contrahegemónica, en El derecho y la globalización desde abajo. Hacia una legalidad cosmopolita, capítulo I, 7-28, 9 (Boaventura de Sousa-Santos \& César A. Rodríguez-Garavito, eds., Carlos F. Morales de Setién-Ravina, trad., Universidad Autónoma Metropolitana, UAM, Cuajimalpa, Anthropos, México, Barcelona, 2007). Disponible en: http://www.boaventuradesousasantos.pt/media/El $\% 20$ derecho $\% 20 \mathrm{y} \% 201 \mathrm{la} \% 20$ globalizaci\%C3\%B3n\%20desde\%20abajo_Anthropos.pdf

11 Ibid., p. 10. 
mación del derecho ante la erosión del poder del Estado, cada vez mayor, poniendo el análisis de instituciones y los actuales procesos económicos como ejes de su perspectiva. Por otra parte, la legalidad cosmopolita responde también a los estudios sobre la hegemonía jurídica global. Tal perspectiva, al tomar como eje a las élites en el concierto internacional, aunque reveladora, resulta limitada, pues invisibiliza a las mayorías marginadas del mundo, las cuales cuentan con capacidad para incidir en los marcos regulatorios actualmente dominantes ${ }^{12}$.

En este sentido, la legalidad cosmopolita se propone proporcionar claridad analítica e instrumentos de traducción que permitan que los esfuerzos de la globalización contrahegemónica sean mutuamente inteligibles. De esta forma, se asume que el cosmopolitismo "sea bajo la forma de las doctrinas de derechos humanos de la Ilustración, el anticolonialismo o los movimientos sociales transnacionales contemporáneos, implica proyectos contrahegemónicos que pretenden superar las jerarquías y las fronteras interestatales"13.

Por otro lado, ya que nuestra investigación se centra en la comprensión del proceso de movilización de un actor subalterno en los canales del Derecho Internacional, es menester considerar los postulados de Balakrishnan Rajagopal, quien explota las herramientas de las ciencias sociales - en especial la sociología jurídica y la sociología política - para describir y analizar el potencial y las limitaciones del uso del derecho internacional por parte de los movimientos sociales.

La obra de Rajagopal tiene dos ejes básicos: las instituciones internacionales y la retórica de los derechos humanos, y cómo estos se han configurado como un elemento de resistencia del Tercer Mundo. Así, esta teoría se ubica en las antípodas de las perspectivas dominantes sobre el derecho internacional, que

12 Boaventura de Sousa-Santos \& César A. Rodríguez-Garavito, El derecho, la politica y lo subalterno en la globalización contrahegemónica, en El derecho y la globalización desde abajo. Hacia una legalidad cosmopolita, capítulo I, 7-28, 17 (Boaventura de Sousa-Santos \& César A. Rodríguez-Garavito, eds., Carlos F. Morales de Setién-Ravina, trad., Universidad Autónoma Metropolitana, UAM, Cuajimalpa, Anthropos, México, Barcelona, 2007).

13 Ibid., p. 18. 
giran en torno a paradigmas específicos de la racionalidad y modernidad occidentales, que predeterminan cuáles son los actores para los que existe el derecho internacional, fundamentalmente los Estados. Esto termina siendo desatinado, porque los patrones de interacción del Tercer Mundo con el Derecho Internacional Público han cambiado y no se puede analizar dentro del paradigma estatal. En síntesis, el "intento de usar una perspectiva desde los movimientos sociales para analizar la resistencia del tercer mundo al derecho internacional es el primero conocido en ocuparse sistemáticamente de los patrones cambiantes de la interacción del tercer mundo con el derecho internacional"14.

Para recapitular, podemos señalar que las investigaciones y perspectivas revisadas contribuyen al entendimiento de la internacionalización de la causa indígena. Todas estas ópticas con una perspectiva crítica (Brysk; Santos \& Rodríguez; Rajagopal; Santamaría) alcanzan una visión integral, pues parten de una gama amplia de actores y experiencias que permite comprender la dinámica de la globalización y el derecho internacional como un escenario en el que confluyen actores en disputa. Empero, estas perspectivas, pese a presentarse como transnacionales, se centran demasiado en el plano internacional y relegan la incidencia que este pueda tener en el plano local.

En este sentido, encontramos que hay tres momentos fundamentales en los cuales el derecho internacional se convierte en garante de derechos. Primero, cuando desde lo local se decide la judicialización y visibilización internacional del problema que aqueja al pueblo indígena en cuestión. En el segundo momento, la estrategia puesta en marcha se soluciona o no en el plano internacional y por ende, en la dimensión formal. Finalmente, el tercer momento significa la repercusión fáctica de la resolución acaecida en el plano internacional o, en otras palabras, es la concreción de los esfuerzos del primer y segundo momento. Este último momento es obviado por todas las perspectivas tratadas

14 Balakrishnan Rajagopal, El derecho internacional desde abajo. El desarrollo, los movimientos sociales y la resistencia del Tercer Mundo, 27 (Instituto Latinoamericano de Servicios Legales Alternativos, ILSA, Bogotá, 2005). 
en este estado de la cuestión, pues asumen que la resolución de la cuestión indígena concluye en el segundo momento, y olvidan así el retorno al plano nacional en el cual las autoridades correspondientes tienen aún la responsabilidad de ejecutar las resoluciones.

Teniendo en cuenta lo anterior, el proceso de resistencia y lucha del pueblo indígena Awá será abordado desde dos categorías de análisis fundamentales que retoman los aportes de los autores antes repasados, aunque evitando adolecer de las debilidades también expuestas. Así pues, en primer lugar, adoptamos los planteamientos de Margaret E. Keck y Kathryn Sikkink (2000), quienes formulan la categoría analítica redes transnacionales de defensa, por la cual se entienden las formas de organización transnacionales caracterizadas por modelos de comunicación e intercambio voluntario, recíproco y horizontal, mediante las cuales los defensores abogan por las causas de otros o defienden una propuesta ${ }^{15}$. De esto se desprende que estas redes están integradas por actores relevantes que trabajan internacionalmente sobre un tema específico y están ligados por un ideario común, y que entre estos fluyen informaciones y prácticas propicias para el logro de un determinado fin. Así pues, como lo señalan las mismas autoras: "Lo nuevo de estas redes es la capacidad de los actores internacionales no tradicionales para movilizar estratégicamente la información, a fin de ayudar a crear nuevos asuntos y categorías, y para convencer, presionar e influir a organizaciones y gobiernos mucho más poderosos que ellos"16.

En segundo lugar, planteamos la categoría instrumentalización subalterna del derecho internacional, partiendo de los planteamientos de Balakrishnan Rajagopal. Este autor considera que el derecho mantiene una relación de ambivalencia en lo que a movimientos sociales concierne. Por un lado, los movimientos sociales conciben el derecho a forma de límite, como un dispositivo del statu quo, por otra parte, lo aprecian como una forma de

15 Margaret E. Keck \& Kathryn Sikkink, Activistas sin fronteras: redes de defensa en politica internacional, 26-27 (Siglo XXI Editores, Ciudad de México, 2000).

16 Ibid., p. 18. 
resistencia. No obstante, en el contexto de la globalización, en el que aparecen factores como la multiescalaridad del derecho (local, nacional, global), la aparición de regímenes jurídicos supranacionales y el crecimiento progresivo de las normas verticales y horizontales en áreas como los derechos humanos, los derechos de los pueblos indígenas y el medio ambiente, se traducen en la proliferación de espacios jurídicos y políticos en los cuales las decisiones judiciales nacionales pueden ser desafiadas por los movimientos sociales ${ }^{17}$; estos han tendido a asumir al derecho como un espacio de resistencia.

Con base en lo anterior, y teniendo en cuenta que nos interesa la escala internacional de acción de tales movimientos, entendemos esta categoría - instrumentalización subalterna del derecho internacional-como la estrategia política de los actores sociales subalternos, en este caso el pueblo Awá, de acudir a instancias internacionales con el fin de lograr cambios jurídicos permanentes para la formalización de sus reivindicaciones y sus consecuentes repercusiones en el plano local.

Encontramos así dos categorías que nos permiten entender las transformaciones que se están dando en las luchas y resistencias de los actores subalternos mundiales, y que por tanto son propicias para estudiar el caso del pueblo indígena Awá. Las perspectivas aquí adoptadas hallan la explicación de tales transformaciones en los procesos de globalización, los cuales no son vistos de una manera homogénea ni tampoco conservan una perspectiva "desde arriba". Todo lo contrario. Se busca indagar cómo los actores subalternos, en el marco de desigualdades existente, son capaces de construir alternativas y/o hacer su propia lectura del contexto para defender sus derechos. Una vez aclarados estos elementos, empezamos un interesante reco-

17 Balakrishnan Rajagopal, Los limites del derecho en la globalización contrahegemónica: la Corte Suprema de la India y la lucha en el valle de Narmada, en El derecho y la globalización desde abajo. Hacia una legalidad cosmopolita, capítulo VIII, 167-196 (Boaventura de SousaSantos \& César A. Rodríguez-Garavito, eds., Carlos F. Morales de Setién-Ravina, trad., Universidad Autónoma Metropolitana, UAM, Cuajimalpa, Anthropos, México, Barcelona, 2007). Disponible en: http://www.boaventuradesousasantos.pt/media/El\%20derecho\%20y\%20la\%20 globalizaci\%C3\%B3n\%20desde\%20abajo_Anthropos.pdf 
rrido analítico por el proceso de resistencia y lucha del pueblo indígena Awá.

\section{CONTRA LA VIDA AwÁ}

Aquí ha habido masacres y seguimos poniendo sangre de compañeros, compañeras, niños, niñas, y la amenaza del Pueblo Awá como tal...

Líder Awá

El control de fuentes económicas a partir de la explotación de recursos naturales - como la minería ilegal de oro, plata y coltán y los cultivos ilícitos de coca y amapola - ha hecho que las zonas rurales colombianas se conviertan en importantes ejes de disputa entre los actores armados. De allí que el control de los corredores estratégicos del narcotráfico revista tanta importancia estratégica como una de sus principales formas de adquisición económica. En el departamento de Nariño, las actividades de este tipo han proliferado, debido al incremento de fumigaciones y operaciones militares desarrolladas por el Estado en Putumayo, lo que ha derivado en que la mayoría de los cultivos ilícitos se trasladó hacia los territorios indígenas Awá y de las comunidades negras ${ }^{18}$. Si a esto se suma la importante conexión que constituye Nariño entre la cordillera Central y el océano Pacífico, pero también con Ecuador, se obtiene que el departamento se ha convertido en un objetivo estratégico para el transporte de armas y drogas, por cuyo control se enfrentan los distintos grupos armados ilegales a fin de proteger sus actividades económicas ${ }^{19}$. Se estima que la guerrilla de las Fuerzas

18 Verdad Abierta, Barbacoas: un olvido, muchos conflictos (13 de mayo de 2015). Disponible en: http://www.verdadabierta.com/victimas-seccion/los-resistentes/5777-barbacoas-narinoun-olvido-muchos-conflictos. Observatorio de Procesos de Desarme, Desmovilización y Reintegración, ODDR, Universidad Nacional de Colombia \& Fondo de las Naciones Unidas para la Infancia, UNICEF, Caracterización del departamento de Nariño (Universidad Nacional de Colombia \& UNICEF, Bogotá, 2011).

19 Efraín Jaramillo-Jaramillo, Tragedia del pueblo indígena Awa, en Los indígenas colombianos y el Estado: desafíos ideológicos y políticos de la multiculturalidad, 188-194 (International Work Group for Indigenous Affairs, Grupo Internacional de Trabajo sobre Asuntos Indígenas, IWGIA, Bogotá, 2011). Disponible en: http://www.iwgia.org/iwgia_files_publications_files/0558_libro_los_indigenas_y_el_estado_2011_COMPLETO.pdf 
Armadas Revolucionarias de Colombia, Farc, y Los Rastrojos ${ }^{20}$ son los grupos armados con mayor presencia en la región y su contacto con la población se manifiesta principalmente en amenazas, desplazamientos e instalación de minas antipersonal ${ }^{21}$.

El año 2009 fue un punto álgido de esta problemática y uno de los más críticos para la supervivencia del pueblo indígena Awá. El 4 de febrero de 2009, miembros de las Farc — la organización insurgente más significativa del país - raptaron a 17 personas del resguardo Tortugaña Telembí, en Barbacoas, atribuyéndoles su colaboración con el Ejército Nacional como supuestos informantes. Entre los retenidos había mujeres y niños, que fueron conducidos hacia una quebrada llamada El Hojal, en la vereda Bravo, donde fueron asesinados. Posteriormente, los mismos guerrilleros volvieron al resguardo y se llevaron a los niños que quedaban en las casas. Tras estos acontecimientos, las autoridades del departamento de Nariño y los voceros de la comunidad Awá se reunieron para verificar la presunta masacre de cerca de 20 indígenas de la etnia.

No siendo suficiente con esto, el 12 de febrero (8 días después) las autoridades indígenas de la Organización Nacional Indígena de Colombia, ONIC, notificaron la muerte de otros diez indíge-

20 De acuerdo con el informe final elaborado por los doce expertos de la Comisión Histórica del Conflicto y sus Víctimas, denominado Contribución al entendimiento del conflicto armado en Colombia, en el marco del acuerdo general suscrito entre el gobierno nacional y las Farc, del 26 de agosto de 2012, los actores principales del conflicto armado de Colombia han sido dos en la primera fase y tres en la segunda, sin dejar de lado otros actores sociales y políticos que cumplen papeles importantes, como manteniendo o profundizando la precariedad institucional o debilidad del Estado; financiando o promocionando grupos armados ilegales, entre otros. En la primera fase (1964-1980), sobresalen la confrontación entre los grupos guerrilleros de la primera generación y las Fuerzas Militares y se caracteriza por el debilitamiento de la guerrilla a finales de los años sesenta y principios de los setenta. En la segunda fase (1980-2015), el conflicto se agudiza tras la aparición de los grupos paramilitares y los recursos financieros sin antecedentes, provenientes del narcotráfico, el secuestro y la extorsión. Lo que dio pie, según algunos académicos, a la aparición de "terceros oportunistas", es decir, organizaciones criminales o agentes políticos, que han buscado obtener beneficios particulares con el conflicto. Eduardo Pizarro-Leongómez, Una lectura múltiple y pluralista de la historia, 48-50, capítulo I, 61-62 (Comisión Histórica del Conflicto y sus Víctimas, Ediciones Desde Abajo, Colombia, Bogotá, 2015). Disponible en: http://www.altocomisionadoparalapaz.gov.co/mesadeconversaciones/PDF/Informe $\% 20$ Comisi_n\%20Hist_rica\%20del $\% 20$ Conflicto $\% 20 \mathrm{y} \% 20$ sus $\% 20$ V_ctimas. $\% 20 \mathrm{La} \% 20 \mathrm{Habana} \% 2 \mathrm{C} \% \overline{2}$ Febrero\%20de\%202015.pdf

21 Fundación Ideas para la Paz, FIP, Dinámicas del conflicto armado en Tumaco y su impacto humanitario (10 de febrero de 2014). Disponible en: http://cdn.ideaspaz.org/media/website/ document/52f8ecc452239.pdf 
nas del resguardo Sandé, entre los municipios de Ricaurte y Guachavés, presuntamente a manos de las Farc. Tres días después fueron asesinados otros dos indígenas Awá, sin saberse a ciencia cierta qué actor armado fue el victimario. Meses más tarde, el 26 de agosto, perdieron la vida 12 indígenas Awá del resguardo indígena Awá Gran Rosario, del municipio de Tumaco, masacre cometida por presuntos paramilitares ${ }^{22}$. Como agravante de los hechos, el pueblo Awá también fue sometido a la pesadilla de las minas antipersonal y el desplazamiento forzado de su territorio, lo que deja hoy un conteo amplio de víctimas. La tabla 1 ilustra los devastadores efectos de la guerra en el territorio Awá durante 2009 (en comparación con 2008):

22 Unidad Indígena del Pueblo Awá, UNIPA; Cabildo Mayor Awá de Ricaurte, CAMAWARI \& Asociación de Cabildos Indígenas del Pueblo Awá del Putumayo, ACIPAP, Actualización plan de salvaguarda étnica del pueblo Awá (Nariño y Putumayo, Colombia, 2012). Disponible en: http://observatorioetnicocecoin.org.co/cecoin/files/P_S\%20Aw\%C3\%A1.pdf 
TABLA 1

SITUACIÓN DE DERECHOS HUMANOS EN NARIÑO, 2008 Y 2009

\begin{tabular}{|l|c|c|}
\hline Categoría & $\mathbf{2 0 0 8}$ & $\mathbf{2 0 0 9}$ \\
\hline Homicidios & 723 & 647 \\
\hline Casos de masacres & 2 & 8 \\
\hline Víctimas de masacres & 9 & 51 \\
\hline Homicidios de alcaldes y exalcaldes & 0 & 0 \\
\hline Homicidios de concejales & 1 & 0 \\
\hline Homicidios de indígenas & 19 & 60 \\
\hline Homicidios de maestros no sindicalizados & 4 & 0 \\
\hline Homicidios de maestros sindicalizados & 1 & 0 \\
\hline Homicidios de sindicalistas de otros sectores & 0 & 0 \\
\hline Homicidios de periodistas & 0 & 0 \\
\hline Secuestro & 18 & 22 \\
\hline Personas desplazadas (por fecha de expulsión) & 31.314 & 17.110 \\
\hline Personas desplazadas (por fecha de declaración) & 29.649 & 17.081 \\
\hline Eventos por minas antipersonal (MAP) & 95 & 56 \\
\hline y municiones sin explotar (Muse) & 44 & 30 \\
\hline Civiles heridos por MAP y Muse & 10 & 6 \\
\hline Civiles muertos por MAP y Muse & 14 & 28 \\
\hline Militares heridos por MAP y Muse & 4 & 8 \\
\hline Militares muertos por MAP y Muse & & \\
\hline
\end{tabular}

Fuentes: Observatorio del Programa Presidencial de Derechos Humanos y Derecho Internacional Humanitario, Vicepresidencia de la República, 2010. Observatorio de Procesos de Desarme, Desmovilización y Reintegración, ODDR, Universidad Nacional de Colombia \& Fondo de las Naciones Unidas para la Infancia, UNICEF, Caracterización del departamento de Nariño (Universidad Nacional de Colombia \& UNICEF, Bogotá, 2011).

Posteriormente, el 25 de diciembre de 2011, un grupo paramilitar retuvo a siete indígenas y produjo el desplazamiento de otras 200 personas. El 26 de febrero de 2012, los combates entre el Ejército y las Farc obligaron a 850 indígenas a abandonar sus tierras y el 13 de marzo de este mismo año, por el grave riesgo en que viven los Awá por la cantidad de minas antipersonal sembradas en su territorio, 40 familias se vieron obligadas a salir de su resguardo en La Hormiga, Putumayo ${ }^{23}$.

23 El Espectador, Redacción Política, La batalla del Pueblo Awá(22 de marzo de 2012). Disponible en: http://www.elespectador.com/noticias/politica/batalla-del-pueblo-awa-articulo-333985 
Este siniestro accionar cobra sentido si se tiene en cuenta que, como lo señaló la Defensoría del Pueblo en su Nota de Seguimiento 001-09, "los grupos armados saben que para controlar un territorio, el método más efectivo es hacer demostraciones de poder mediante el uso de la violencia. Esto significa doblegar la resistencia de los pobladores para imponer pautas de conducta que determinen el reconocimiento de su autoridad"24. Así pues, es evidente cómo estos mecanismos de amedrentamiento a la población civil, en este caso el Pueblo Awá, son utilizados como estrategias de guerra cuyo único fin es el empoderamiento de las partes en conflicto.

Ahora bien, es preciso poner de relieve que estos atroces actos se habrían podido prevenir. Los Awá desde 2008 insistieron en que ellos tenían autonomía sobre sus territorios y por tanto, el Ejército Nacional no debía hacer operativos contrainsurgentes en estos, incluso llegaron a proponer su traslado, con ayuda de la ONU, a otra zona mientras se realizaban los enfrentamientos ${ }^{25}$. Empero, la respuesta del establecimiento - como es comúnfue la desidia, lo que se evidenció en las palabras que algunos años más tarde pronunció el coronel Juan Carlos Lara, de la XXIII Brigada del Ejército Nacional, con sede en Pasto, respecto del pueblo Awá y el conflicto armado. Dijo el coronel: "Le estoy diciendo que la guerra o el conflicto no se están llevando en las montañas, no se está llevando en un campo despejado, se está llevando en áreas habitadas en medio de las comunidades. Las comunidades son parte del Estado y como tal tienen que colaborar porque o si no esto nunca se va a acabar" ${ }^{\prime 26}$.

24 Defensoría Delegada para la Evaluación de Riesgos de la Población Civil como consecuencia del Conflicto Armado, Nota de Seguimiento No. 001-09 (Bogotá, 2009). Disponible en: http:// sisat.defensoria.org.co/subsitio/doc/historicoAdvertencia/Notas2009/NS\%20N\%C2\%B0\%20 001-09\%20a\%20IR\%20N\%C2\%B0\%20029-07\%20A.I\%20Barbacoas,\%20Roberto\%20 Pay\%C3\%A1n\%20y\%20Magu\%C3\%AD\%20Payan-NARI\%C3\%91O.pdf

25 Revista Semana, Las masacres anunciadas de Nariño (13 de febrero de 2009). Disponible en: http://www.semana.com/nacion/conflicto-armado/articulo/las-masacres-anunciadasnarino/100085-3

26 Hollman Morris (prod.), El pueblo Awá: Aprender y luchar para resistir el engaño [serie de televisión Contravía, capítulo 275] (Morris Producciones, Bogotá, 2012). Disponible en: https:// www.youtube.com/watch?v=QwJq-DMysjc 
De esta manera, el gobierno nacional desatendió tan urgente llamado para la salvaguardia de los indígenas Awá y esos fueron los resultados. Frente a esto, con gallardía, el Pueblo Awá organizó la Minga Humanitaria por la Vida y por la Paz, para llamar la atención del pueblo colombiano y la comunidad internacional. La magnitud de los hechos despertó el rechazo de entes internacionales como el G-24, Human Rights Watch y organismos como la Comisión Interamericana de Derechos Humanos, CIDH y la Oficina del Alto Comisionado de Naciones Unidas para los Refugiados, ACNUR; así mismo, de instituciones como la Organización de Estados Americanos (OEA), que condenaron los acontecimientos perpetrados contra los Awá.

Desde estos infames episodios, el pueblo Awá no ha tenido un minuto de paz, pues uno tras otro se suceden actos de terror en su contra, principalmente por parte de los actores armados del conflicto. Por ello, los años posteriores a las masacres fueron de lucha constante con el propósito de que el Estado garantice plenamente sus derechos a la vida, a la cultura y al territorio. En ese sentido, el primer escenario de lucha se dio en los canales del derecho interno, cuestión que abordaremos en el siguiente apartado.

\section{EN DEFENSA DE LA VIDA AwÁ}

\section{A. En el plano nacional}

1. El pueblo Awá reivindica sus derechos

Ante la gravísima crisis humanitaria antes descrita, el Estado colombiano en cabeza de la Corte Constitucional emitió el Auto A-004-0927 para la protección de los derechos fundamentales de las personas y los pueblos indígenas desplazados por el conflicto armado interno o en riesgo de desplazamiento forzado, en

27 Colombia, Corte Constitucional, Sala Segunda de Revisión, Auto A-004-09, 26 de enero de 2009, magistrado ponente Manuel José Cepeda-Espinosa. Disponible en: http://www.corteconstitucional.gov.co/relatoria/autos/2009/a004-09.htm 
el marco de la superación del estado de cosas inconstitucional declarado en la sentencia T-025-0428 ante la vulnerabilidad de la población desplazada.

Mediante el Auto A-004-09, la Corte Constitucional declaró a los Awá como un "pueblo en vía de extinción" a causa del conflicto armado, junto con otras 34 comunidades indígenas, y ordenó al gobierno nacional el diseño y materialización de un Plan de Salvaguarda Étnica. Así, dictaminó "que [se] formulen e inicien la implementación de planes de salvaguarda étnica ante el conflicto armado y el desplazamiento forzado para cada uno de los pueblos identificados en la presente providencia", y que "Estos planes de salvaguarda étnica deben responder, tanto en el ámbito de la prevención del desplazamiento forzado como de la atención a sus víctimas" 29 .

Valiéndose de su derecho a la consulta previa, entre julio de 2009 y marzo de 2010, el pueblo Awá construyó participativamente su propio Plan de Salvaguarda Étnica del Pueblo Indígena Awá, PSEA. Sin embargo, hasta hoy, el esfuerzo de los Awá ha sido en vano; como lo expone un líder de la comunidad: "Hoy [11 de septiembre de 2015] llevamos seis años siendo pioneros en la formulación y construcción de los planes de salvaguarda, pero el pueblo Awá no tiene un plan de salvaguarda protocolarizado (sic), hoy el plan de salvaguarda no se ha implementado por más que tenemos el auto A-174-11 ${ }^{30}$, que es un auto específico para el pueblo Awá, donde dice la Corte que hay que ponerle atención"31.

En consonancia, debido al incumplimiento gubernamental de las determinaciones del auto A-004-09, en agosto de 2011, por medio del Auto A-174-11 —exclusivo para el pueblo Awá-, la

28 Colombia, Corte Constitucional, Sentencia T-025-04, 22 de enero de 2004, magistrado ponente Manuel José Cepeda-Espinosa. Disponible en: http://www.corteconstitucional.gov.co/ relatoria/2004/t-025-04.htm

29 Colombia, Corte Constitucional, Sala Segunda de Revisión, Auto A-004-09, 26 de enero de 2009, magistrado ponente Manuel José Cepeda-Espinosa, Medidas a adoptar, segundo. Disponible en: http://www.corteconstitucional.gov.co/relatoria/autos/2009/a004-09.htm

30 Colombia, Corte Constitucional, Sala Especial de Seguimiento, Auto A-174-11, 9 de agosto de 2011, magistrado ponente Luis Ernesto Vargas-Silva. Disponible en: http://www.corteconstitucional.gov.co/relatoria/autos/2011/a174-11.htm

31 Entrevista a líder indígena Awá, Llorente, Tumaco, septiembre de 2015. 
Corte Constitucional reiteró su dictamen y ordenó la elaboración de un Plan Provisional Urgente de Reacción y Contingencia que atendiera de manera inmediata e integral las necesidades más imperiosas de seguridad física y atención humanitaria. En lo que respecta al seguimiento de las medidas cautelares de la CIDH - aspecto en el que profundizaremos más adelante-, invitó a la Comisión a conformar un cuerpo para verificar su cumplimiento. Con este respaldo jurídico, el pueblo Awá ha propugnado por una solución a sus problemas mediante el diálogo con el gobierno nacional.

En 2010, los Awá solicitaron la creación de una mesa de concertación con el Ministerio de Interior y de Justicia, la Agencia Presidencial para la Acción Social y la Cooperación Internacional, y el Programa Presidencial de Derechos Humanos de la Presidencia de la República, la cual fue instituida mediante el Decreto 1137 de $2010^{32}$. Sin embargo, a la fecha, tal formalidad no ha tenido los efectos esperados, permitiendo que el exterminio del pueblo Awá continúe. La falta de voluntad política del gobierno, la formulación de planes de atención a las víctimas de naturaleza paliativa y no transformativa, y el desconocimiento de las especificidades culturales de este pueblo indígena por parte de la institucionalidad estatal han sido las principales fallas en este proceso de concertación.

De esta manera, el pueblo Awá ha recorrido los caminos institucionales del Estado colombiano sin encontrar una verdadera satisfacción para sus reivindicaciones pero sí, más bien, sumando frustraciones. Ante esto, a la luz de los planteamientos de Keck y Sikkink, la puesta en marcha de una estrategia en el plano internacional es comprensible y hasta lógica; como ellas lo expresan: "Cuando un gobierno viola los derechos o se niega a reconocerlos los individuos y los grupos nacionales muchas veces carecen de recursos dentro de los escenarios nacionales políticos y judiciales. Puede que al fin busquen conexiones in-

32 Colombia, Decreto 1137 de 2010, por el cual el Gobierno Nacional crea la Mesa de Concertación para el Pueblo Awá, 47.679 Diario Oficial, 13 de abril de 2010. Disponible en: https://www. minjusticia.gov.co/portals/0/MJD/docs/decreto_1137_2010.htm 
ternacionales para expresar sus preocupaciones e, incluso, para proteger sus vidas" 33 .

Es momento entonces de continuar con el abordaje del proceso de lucha y resistencia del pueblo Awá en el plano internacional, a partir de las redes de defensa transnacionales y la instrumentalización subalterna del derecho internacional.

\section{B. La lucha Awá en el plano internacional}

1. Para tejer vínculos más allá de las fronteras nacionales

Entonces hoy los elementos internacionales y las visitas en otros países realmente funcionan, no es que sean ágiles, pero sí logran que el gobierno $o$ la institucionalidad comiencen a andar.

Líder Awá

Según lo manifestado en el informe realizado por la ONIC y presentado ante la CIDH sobre la situación de derechos humanos de los pueblos indígenas en Colombia, cada vez hay más evidencias de que el abandono de las políticas de Estado en los territorios indígenas y el estancamiento de las políticas públicas para lograr el total desarrollo de los derechos reconocidos a estos pueblos, hacen parte de la estrategia de desarraigo a la población autóctona para cambiar el destino económico del suelo de los territorios indígenas. Esta estrategia ha sido resistida por el pueblo indígena Awá, como lo expresamos anteriormente, mediante los canales internos del Estado, es decir, exigiendo el cumplimiento de los autos A-004-09 y A-174-11, y mediante la solicitud de una mesa de concertación para la satisfacción de las reivindicaciones de los Awá.

No obstante, el gobierno nacional se ha hecho el de la vista gorda, lo que ha obligado al pueblo indígena Awá a emprender su lucha en el plano internacional, mediante las redes de defensa y los canales del derecho internacional. La abogada Carolina

33 Margaret E. Keck \& Kathryn Sikkink, Activistas sin fronteras: redes de defensa en politica internacional, 32 (Siglo XXI Editores, Ciudad de México, 2000). 
Sáchica, encargada del caso del pueblo indígena Wayúu ante la $\mathrm{CIDH}^{34}$, corrobora esto; ella expresa: “(...) se acude a una instancia internacional cuando la estructura del Estado no está en capacidad de proteger los derechos fundamentales y hay un peligro inminente para la sociedad civil (..." ${ }^{\prime 35}$.

Ahora bien, trayendo a colación la categoría de redes transnacionales de defensa, hay que indicar que las condiciones de posibilidad de estas se dan cuando: a) ante una situación de conflicto, los conductos regulares entre los sectores sociales y los gobiernos nacionales están bloqueados o no son fluidos para su resolución; b) hay confianza por parte de los activistas en que la red contribuirá al logro de sus reivindicaciones o intereses y por tanto, las impulsan; y c) hay formas de contacto internacional propicias para la creación de redes y su fortalecimiento ${ }^{36}$. Como ya lo habrá notado el lector agudo, la primera condición es cumplida a cabalidad por el pueblo Awá, manifestada en la ineficiencia de los canales y la falta de voluntad del gobierno nacional para con su problemática. Es pues necesario revisar las condiciones restantes.

Conviene, en primer lugar, señalar que en el marco de la grave crisis humanitaria del pueblo Awá en 2009, la ONIC, organización a la que está adscrita la Unidad Indígena del Pueblo Awá, UNIPA, jugó un papel fundamental para concertar la visita de James Anaya, relator especial de la ONU para los pueblos indígenas, a la comunidad indígena afectada. Como bien lo recoge Mónica Acosta, el logro de esta visita se debe a un proceso de lobby e incidencia de organizaciones indígenas y ONG en diversas instancias, como el Foro Permanente para las Cuestiones Indígenas de la ONU, la vigésimo cuarta sesión del Grupo de Trabajo de Políticas Indígenas (GTPI) y la primera

34 En la actualidad, el pueblo indígena Wayúu, con colaboración del Consultorio Jurídico de la Universidad Jorge Tadeo Lozano, lleva a cabo el proceso de denuncia ante la CIDH por la crítica situación humanitaria que vivencia, a causa de la privatización del río Ranchería por la empresa extractivista Cerrejón.

35 Entrevista a Carolina Sáchica, Bogotá, septiembre de 2015.

36 Margaret E. Keck \& Kathryn Sikkink, Activistas sin fronteras: redes de defensa en política internacional, 31 (Siglo XXI Editores, Ciudad de México, 2000). 
sesión del Mecanismo de Expertos sobre los Derechos de los Pueblos Indígenas de 2008. Así pues, el gobierno nacional fue presionado para que invitara a Anaya al país, de tal forma que en julio de 2009, en el contexto del seguimiento de las recomendaciones expresadas en 2004 por el anterior relator Rodolfo Stavenhagen, el experto visitó Colombia. El corregimiento de El Diviso, territorio Awá, estuvo en su agenda. Esta visita fue aprovechada por la UNIPA para poner de presente la grave violación de los derechos humanos de su pueblo y sus repercusiones para su pervivencia física y cultura ${ }^{37}$.

A lo sumo, esto terminó en la elaboración de un informe del relator especial que consigna las conclusiones y recomendaciones para el gobierno colombiano para la efectiva protección de los derechos de los pueblos indígenas. Un elemento a destacar de este informe es que determinó que "la situación de los pueblos indígenas en el país no ha sido afrontada con la urgencia que la gravedad de la situación merece" ${ }^{38}$. Esta situación ya había sido descrita por el relator anterior, en el informe de 2004 como “(...) grave, crítica y profundamente preocupante" 39 . En este orden de ideas, se instó al Estado para la adopción efectiva de políticas públicas que garanticen la protección de los derechos indígenas e igualmente invitó al gobierno nacional a buscar una solución negociada al conflicto armado interno que redunde en el cese de la violencia contra los pueblos indígenas.

De lo anterior, se desprende el nuevo interés de las comunidades indígenas, entre ellas los Awá, por conquistar espacios de poder en el plano internacional que permitan la visibilización de la situación de los pueblos indígenas y atraigan la mirada de la cooperación internacional, en este caso del exrelator especial James Anaya. Esto debido a que se ha desarrollado la creencia

37 Mónica N. Acosta-García, Aproximación al estudio de redes transnacionales de defensa y prácticas de Derechos Humanos: análisis de la incidencia de la ONIC en la Organización de las Naciones Unidas. El caso del desplazamiento forzado de los Pueblos Indigenas Emberas..., 57-130, 99.

38 Ibid., p. 105.

39 Ibid., p. 104. 
en que tales instancias pueden brindar apoyo y otorgar mayor legitimidad a sus reivindicaciones.

Pero antes de continuar, hay una cuestión que falta resolver aquí: ¿cómo se logran los contactos internacionales que permiten la creación de las redes de defensa transnacional? Pues bien, encontramos elementos como la experiencia organizacional; en el caso de la UNIPA, de más de 25 años en los que la organización ha logrado un reconocimiento nacional que ha posibilitado su introducción en el plano internacional; en segunda medida, hay un factor concerniente a la especificidad de su situación, pues en el caso de los Awá el hecho de que sea un pueblo tan crudamente golpeado por la violencia, hasta llegar a ser reconocido por la Corte Constitucional colombiana como un pueblo en peligro de exterminio físico y cultural, ha despertado la solidaridad internacional; por último, habría un elemento contextual, este es el posicionamiento del tema en la agenda de intereses globales, que en el caso de los pueblos indígenas se expresa en el creciente posicionamiento de la "cuestión indígena".

Al respecto, quién mejor para expresar esto en términos mucho más prácticos que un miembro de la comunidad Awá:

La UNIPA tiene un proceso de organización de veinticinco años, en los que ha demostrado su capacidad administrativa y política dentro del departamento, pero también ha demostrado su capacidad de relacionamiento institucional y eso ha hecho que en el buen trabajo de diligenciamiento con las autoridades, se haya logrado que tengamos aliados importantes como la cooperación internacional (...) Podemos decir que el pueblo Awá, y todo el proceso de fortalecimiento fue con el apoyo de la Comisión Internacional y con cooperaciones, con las que hemos estado haciendo vínculos, que nos han estado ayudando para que salgamos a espacios ${ }^{40}$.

Con estas palabras es palpable cómo el pueblo Awá ha puesto en marcha una estrategia de internacionalización de su causa, mediante redes transnacionales de defensa en las que interactúan con organizaciones sociales internacionales y con organismos internacionales. Así mismo, dan cuenta de cómo se

40 Entrevista a líder indígena Awá, Llorente, Tumaco, septiembre de 2015. 
ha dado el proceso de generación de contactos internacionales indispensables para el funcionamiento de estas redes. Es deber ahora explorar los vínculos que el pueblo Awá ha construido y aún hoy fortalece.

El pueblo indígena Awá cuenta hoy con aliados como ONG internacionales, organismos internacionales, entre ellos: el Comité de Oxford de Ayuda contra el Hambre, OXFAM Internacional; la Oficina de Naciones Unidas para la Coordinación de Asuntos Humanitarios, OCHA; la Oficina del Alto Comisionado de las Naciones Unidas para las Refugiados, ACNUR; Fondo de Población de las Naciones Unidas, UNFPA; el Comité Internacional de la Cruz Roja, CICR; el Llamamiento de Ginebra, Geneva Call; la Fundación Española para la Cooperación Solidaridad Internacional; Amnistía Internacional, AI; Human Rights Watch, HRW; y el Observatorio (catalán) por la Autonomía y los Derechos de los Pueblos Indígenas en Colombia (ADPI). Todo este entramado de entes internacionales ha contribuido en mayor o menor medida al pueblo indígena Awá, mediante la atención directa y/o la visibilización internacional de sus problemáticas. No obstante, queremos reparar en el Observatorio ADPI, ya que ha sido una de las organizaciones con mayor incidencia respecto de la problemática Awá.

El Observatorio ADPI, el Instituto Catalán Internacional por la Paz (ICIP) y la Taula Catalana por la Paz y los Derechos Humanos en Colombia, con colaboración de la UNIPA, realizaron un informe en 2012 con el fin de solicitar a la ONU y a la Corte Penal Internacional (CPI) la protección del pueblo indígena Awá. El informe expone con crudeza la violación de derechos humanos contra este pueblo, así: "Señores y señoras de la ONU y la Corte Penal Internacional: a este pueblo lo están asesinando, masacrando a la luz del día, a los ojos de los organismos internacionales, con plena conciencia de que se trata de un exterminio y el gobierno de Bogotá no hace nada serio, nada responsable para evitarlo"4l.

41 Observatorio por los Derechos y la Supervivencia de los Pueblos Indígenas de Colombia, OPIC, 
Para argumentar esta mordaz posición, el Observatorio hizo un recuento de las masacres, desplazamientos forzados, violaciones a derechos humanos, violaciones a mujeres, minas antipersonal, explotación de oro en el territorio, etcétera. Todo esto para instar al Estado colombiano a garantizar los derechos de los Awá. Por su parte, el pueblo indígena Awá ha recibido con buenos ojos la solidaridad expresada por esta organización, pues además de lo anteriormente referenciado, recientemente Tica Font, directora del Instituto Catalán Internacional por la Paz, ICIP, visitó Colombia. Así lo narra un líder del pueblo Awá: "(...) Y eso nos ha servido bastante porque el 10 y 11 de mayo [de 2015], estuvimos en un comité de veeduría internacional aquí en Colombia, y vino la doctora de Barcelona [Tica Font], en Bogotá, y eso nos sirvió de mucho porque las herramientas nacionales existen, pero muy pocas veces le monta presión a eso, pero en los instrumentos internacionales hay fuerza (...)"42.

En suma, este primer momento de la puesta en marcha de la estrategia de las redes transnacionales de defensa proyectó un escenario prometedor para el pueblo indígena Awá en su lucha por la defensa de su territorio, su vida y su cultura. Esto podría explicar en parte por qué recurrieron a los canales del derecho internacional en pro de una formalización de sus reivindicaciones que, claro, se materialice en lo local, en sus territorios. De esta forma, la instrumentalización subalterna del derecho internacional se erigió como una segunda estrategia de resistencia, la cual será tratada a continuación.

2. Denuncia y resistencia en el Derecho Internacional

Porque a nosotros de nada nos ha servido estar en Colombia dando vueltas en un mismo círculo con las mismas instituciones y cooperaciones, donde no se ha visto nada de avances o un reconocimiento más a nivel internacio-

SOS a la ONU y la Corte Penal Internacional sobre el exterminio del pueblo Awá de Colombia, 2 (Barcelona, 2012). Disponible en: http://viva.org.co/cajavirtual/svc0307/pdfs/articulo308_307. pdf

42 Entrevista a líder Awá, Llorente, Tumaco, septiembre de 2015. 
nal, por eso nosotros hemos decidido que no solo se quede la visibilidad en Colombia, sino en otros países.

Como instancia jurídica, la CIDH es "un órgano principal y autónomo de la OEA encargado de la promoción y protección de los derechos humanos en el continente americano del Sistema Interamericano de Protección de los Derechos Humanos $(\mathrm{SIDH})^{943}$. Esta instancia se ha ido posicionando cada vez más como un objetivo en la agenda de los actores subalternos, debido a su poder de presión hacia los Estados americanos en materia de derechos humanos ${ }^{44}$.

Frente a este panorama promisorio, el pueblo Awá puso en marcha lo que denominamos estrategia de instrumentalización subalterna del derecho internacional, con objeto de presionar al gobierno colombiano para cumplir las disposiciones de la Corte Constitucional más arriba expuestas. En este sentido, el pueblo Awá denunció su situación ante la CIDH en 2011, apoyado en el informe elaborado en colaboración con el Observatorio PIC y bajo el amparo de dos instrumentos jurídicos internacionales: el Convenio 169 de la OIT sobre Pueblos Indígenas y Tribales de Países Independientes y la Declaración de las Naciones Unidas sobre los Derechos de los Pueblos Indígenas ${ }^{45}$, los cuales son

43 Organización de Estados Americanos, OEA, ¿Qué es la CIDH? (OEA, Washington, 2015). Disponible en: http://www.oas.org/es/cidh/mandato/que.asp

44 Hay una tendencia cada vez más fuerte a demandar la garantía de los derechos indígenas en instancias jurídicas internacionales como esta, lo que se evidencia en casos como el del pueblo indígena Kichwa, de Sarayaku, Ecuador, que denunció la violación de sus derechos al consentimiento informado y a la autonomía territorial ante la CIDH, a causa de la indiscriminada explotación petrolera de la empresa argentina Compañía General de Combustibles, CGC, en su territorio, logrando en 2003 la expedición de medidas cautelares que fueron desoídas por el gobierno de Ecuador. Ante esto, la CIDH solicitó a la Corte Interamericana de Derechos Humanos que se pronunciara sobre el caso; en 2005, esta Corte dictó medidas provisionales que el gobierno tuvo que acatar. Otro ejemplo similar, en este caso colombiano, es el del pueblo indígena U'wa ubicado en el noreste del país. Sucintamente, este caso consistió en la lucha de esta comunidad indígena contra la transnacional petrolera Oxy, a causa de la exploración petrolífera dentro de sus territorios ancestrales, lo cual terminó en la visibilización, judicialización e internacionalización de esta situación. Ante la denuncia interpuesta por este pueblo en la CIDH y la presión política de ONG internacionales, la multinacional abandonó el territorio.

45 Organización Internacional del Trabajo, OIT, Convenio 169 sobre Pueblos Indígenas y Tribales en Países Independientes, Ginebra, 27 de junio de 1989. Disponible en: http://www.ilo.org/dyn/ normlex/es/f?p=NORMLEXPUB:12100:0::NO::P12100_INSTRUMENT_ID:312314. Organización de Naciones Unidas, ONU, Declaración de las Naciones Unidas sobre los Derechos de 
resultado del creciente interés de las instancias internacionales de derechos humanos por la situación de los pueblos indígenas. Por tanto, se hace importante revisarlos.

En primer lugar, el Convenio de la OIT fue expedido en 1989 y fue el primer organismo internacional en tomar cartas en el asunto. Este convenio es la evolución del Convenio 107 de $1957^{46}$ del mismo organismo, el cual había sido duramente criticado por su enfoque paternalista y asimilacionista. Entre los derechos y principios que reconoce el Convenio 169 están el principio de no discriminación (artículos 3,4, 20 y 24); los derechos a la propiedad de sus territorios ancestrales; al respeto de su identidad cultural (artículos 2, 5 y 7); a la autodeterminación de sus modelos de desarrollo (artículo 7); y a la participación en las decisiones que los afectan (artículos 6, 7 y 15) ${ }^{47}$.

Este convenio fue ratificado por el Estado colombiano en 1991 y hace parte del bloque de constitucionalidad, por lo cual brinda un marco positivo para la protección de los derechos de los pueblos indígenas que es de obligatorio cumplimiento. Por otro lado, instancias internacionales de carácter judicial como la Corte Interamericana de Derechos Humanos han incorporado a su jurisprudencia el Convenio 169 de la OIT, como parte de su cuerpo normativo para la protección internacional de los derechos de los pueblos indígenas ${ }^{48}$.

La Declaración Universal de Derechos de los Pueblos Indígenas es un avance histórico en el reconocimiento de los derechos de estos pues universaliza derechos mínimos para su pervivencia digna. Esta se funda en la Carta de las Naciones Unidas y en la Declaración Universal de los Derechos Humanos, e incorpora

los Pueblos Indígenas, 13 de septiembre de 2007. Disponible en: http://www.un.org/esa/socdev/ unpfii/documents/DRIPS_es.pdf

46 Organización Internacional del Trabajo, OIT, Convenio 107 sobre poblaciones indígenas y tribuales, Ginebra, 26 de junio de 1957. Disponible en: http://www.ilo.org/dyn/normlex/es/f? $\mathrm{p}=$ NORMLEXPUB:12100:0::NO::P12100_ILO_CODE:C107

47 María Clara Galvis-Patiño \& Ángela María Ramírez-Rincón, Manual para defender los derechos de los pueblos indigenas, 10 (Due Process of Law Foundation, DPLF, Washington D.C., 2012). Disponible en: http://www.dplf.org/sites/default/files/manual_de_pueblos_indigenas. pdf

48 Ibid., p. 10. 
además derechos propios de los pueblos indígenas. Aunque esta declaración no cuenta con fuerza vinculante, dado que no tiene carácter convencional, sí ha significado la consagración de derechos, desde la perspectiva de los pueblos y personas indígenas, en otros instrumentos jurídicos ya ratificados por los Estados que sí son vinculantes, como el Pacto de Derechos Civiles y Políticos y el Pacto de Derechos Económicos, Sociales y Culturales ${ }^{49}$ y otras normas fundadas en la costumbre internaciona ${ }^{50}$.

Pese a esto, el Estado colombiano se abstuvo de suscribirla en primera instancia, con el argumento de que la Declaración contrariaba el ordenamiento jurídico interno. Sin embargo, lo que estaba detrás de la negación eran los intereses estratégicos del Estado en la explotación de recursos naturales y la agroindustria, para los cuales los territorios indígenas son claves. Así mismo, bajo la doctrina de seguridad democrática, la Declaración suponía un impedimento para la fuerza pública, esto es, la militarización de los territorios indígenas ${ }^{51}$. No obstante, el Estado colombiano en abril de 2009 aprobó la Declaración y se comprometió a cumplir con su espíritu y respetar sus principios, dado que esto le significaba un reconocimiento positivo frente a la comunidad internaciona ${ }^{52}$. Empero, fue ante todo un formalismo jurídico que no se tradujo en cambios en la relación del Estado con los pueblos indígenas, aunque sí ha servido como un nuevo instrumento de presión y legitimación para estos.

49 Organización de Naciones Unidas, ONU, Pacto de Derechos Civiles y Políticos, 16 de diciembre de 1966. Disponible en: http://www.ohchr.org/SP/ProfessionalInterest/Pages/CCPR.aspx. Organización de Naciones Unidas, ONU, Pacto de Derechos Económicos, Sociales y Culturales, 16 de diciembre de 1966. Disponible en: http://www.ohchr.org/SP/ProfessionalInterest/Pages/ CESCR.aspx

50 María Clara Galvis-Patiño \& Ángela María Ramírez-Rincón, Manual para defender los derechos de los pueblos indigenas, 12 (Due Process of Law Foundation, DPLF, Washington D.C., 2012).

51 Pablo Daniel Barrios-Giraldo \& Carlos Andrés Zapata-Cardona, Declaración de las Naciones Unidas sobre los Derechos de los Pueblos Indigenas: un nuevo reto para Colombia, 27 (Centro de Cooperación al Indígena, CECOIN, Organización Indígena de Antioquia, OIA, Bogotá, 2009). Disponible en: http://observatorioetnicocecoin.org.co/cecoin/files/Cartilla.pdf

52 Oficina del Alto Comisionado de Naciones Unidas para los Refugiados, ACNUR, El ACNUR da la bienvenida a la decisión de Colombia de apoyar la Declaración de la ONU sobre los Derechos de los Pueblos Indigenas (24 de abril de 2009). ACNUR. Disponible en: http://www. acnur.org/noticias/noticia/el-acnur-da-la-bienvenida-a-la-decision-de-colombia-de-apoyar-ladeclaracion-de-la-onu-sobre-los-derechos-de-los-pueblos-indigenas/ 
Ya en 1998, aunque no sin críticas, Boaventura de SousaSantos daba cuenta de este fenómeno de producción de nuevos instrumentos que servían a las luchas por derechos colectivos de los indígenas. Respecto del Convenio 169 de la OIT y en ese entonces el Proyecto de la Declaración Universal de los Derechos de los Pueblos Indígenas de las Naciones Unidas, De SousaSantos expresaba que "La reivindicación de derechos colectivos por parte de los pueblos indígenas y las minorías étnicas está ganando fuerza en el programa político internacional, respaldada por una coalición transnacional amplia y creciente" ${ }^{53}$. Esta última referencia de Boaventura de Sousa-Santos se entiende como la unión de $\mathrm{ONG}$ - indígenas y no indígenas - que han estado llamando la atención al mundo sobre la violación de los derechos de los pueblos indígenas, y presionando a los Estados para detener tal situación ${ }^{54}$.

En este sentido, el uso de las anteriores herramientas ha sido incorporado en los repertorios de acción de los pueblos indígenas para visibilizar y denunciar la violación de derechos humanos de la que son víctimas en pos de la formalización de sus reivindicaciones. En el caso de los Awá, esto se traduce en la perspectiva de que el derecho puede ser utilizado como una herramienta que, a pesar de no encajar en su cosmovisión, sirve como forma de resistencia. Bajo estos argumentos, la denuncia de su crítica situación ante la CIDH evidencia un amplio proceso de instrumentalización subalterna del derecho internacional. Para sintetizar esta postura, las palabras de uno de los líderes son ilustrativas: "realmente consideramos que esas herramientas, los convenios y tratados internacionales, son de vital importancia como bien lo manifiesta el Convenio 169 de la OIT, respecto a la consulta previa a las comunidades indígenas" 55 .

Retomando, por la denuncia realizada por el pueblo Awá ante la CIDH, en 2011 este órgano profirió medidas cautelares

53 Boaventura de Sousa-Santos, La globalización del derecho. Los nuevos caminos de la regulación y emancipación, 160 (Instituto Latinoamericano de Servicios Legales Alternativos, ILSA, Bogotá, 1998).

54 Ibid., p. 152.

55 Entrevista a líder Awá, Llorente, Tumaco, septiembre de 2015. 
en su favor ${ }^{56}$. En estas, la Comisión Interamericana solicitó al Estado de Colombia adoptar medidas consensuadas con los beneficiarios para garantizar la vida y la integridad personal de los miembros del pueblo indígena Awá de los departamentos de Nariño y Putumayo, que incluyan acciones de desminado del territorio ancestral y de educación en el riesgo de las minas antipersonal para los miembros del pueblo ${ }^{57}$.

Frente a esto hay que anotar que si bien en Colombia hay un debate en torno a la vinculatoriedad de las medidas cautelares de la CIDH, afirmamos acá que estas sí son vinculantes, no solo por lo arriba expuesto concerniente a la fuerza jurídica del Convenio 169 y la Declaración Universal de Derechos de los Pueblos Indígenas; sino también porque si nos fundamos en la jurisprudencia de la Corte Constitucional, encontramos que este tribunal tiene una trayectoria jurisprudencial en la cual ha consolidado una doctrina que ha favorecido la vinculatoriedad de esas medidas para todas las autoridades del Estado. Respecto de las medidas cautelares al pueblo Awá, estas no iban a ser la excepción.

Así, en primer lugar, la Corte Constitucional ordenó en el Auto A-174 al Ministerio del Interior la adopción de un plan provisional urgente de reacción y contingencia para el pueblo indígena Awá, que solventase las necesidades más apremiantes de la comunidad como su seguridad física — incluida la relativa al desminado humanitario-, para superar la crisis humanitaria. Por otra parte, respecto a las medidas cautelares el Tribunal colombiano las ratificó y además resolvió:

56 Estas medidas son mecanismos mediante los cuales la CIDH pretende prevenir daños irreparables frente a las situaciones de amenaza a los derechos de las personas. La finalidad es fijar al Estado un proceder inmediato para evitar daños irreparables. Organización de Estados Americanos, OEA, ¿Qué es la CIDH? (OEA, Washington, 2015). Disponible en: http://www. oas.org/es/cidh/mandato/que.asp

57 Comisión Interamericana de Derechos Humanos, CIDH, Informe Anual 2011, Capítulo III, El sistema de peticiones y casos individuales (Comisión Interamericana de Derechos Humanos, 2011). Disponible en: https://www.oas.org/es/cidh/docs/anual/2011/Cap3C1.doc. Comisión Interamericana de Derechos Humanos, CIDH, Medidas cautelares, MC 61/11, Miembros del pueblo indígena Awá de los departamentos de Nariño y Putumayo, Colombia, 16 de marzo de 2011. Disponible en: http://www.oas.org/es/cidh/decisiones/cautelares.asp 
Invitar a la Comisión Interamericana de Derechos Humanos, CIDH, para que en el marco de sus competencias y de la solicitud elevada ante el Estado colombiano, relativa a la adopción de medidas urgentes para preservar la vida e integridad personal de los miembros del pueblo indígena Awá, afectados por la siembra de minas antipersona en su territorio, conforme una comisión de verificación respecto a la adopción de las mismas, así como en cuanto atañe a la situación actual de vulnerabilidad y riesgo de esta comunidad tradicional asentada en el país, en los departamentos de Nariño y Putumayo ${ }^{58}$.

Esta invitación también fue extendida por la Corte a organizaciones que han estado atentas al caso Awá, como la Oxfam International, el Consejo Noruego para Refugiados, NRC, y la Oficina de Naciones Unidas para los Refugiados, ACNUR, para realizar la veeduría al gobierno nacional en el cumplimiento de las medidas señaladas. No obstante, el gobierno colombiano ha soslayado mayormente lo dictado por la Corte Constitucional y las medidas cautelares otorgadas por la CIDH al pueblo Awá.

Pasado un año, el gobierno colombiano tan solo había realizado, por medio del Programa de Acción Integral contra las Minas Antipersonal, PAICMA, una promesa de estrategia de educación en riesgo para las minas antipersonal, como ya se ha indicado, sin que el desminado humanitario se considerara el núcleo de la medida. Ante ello, los Awá organizaron una misión de seguimiento a las medidas cautelares, la cual consistió en una visita a la sede de la CIDH en Washington ${ }^{59}$. Esta tuvo como fin elevar un reclamo frente a la indiferencia del gobierno nacional ante la situación del pueblo Awá. Además, los indígenas realizaron nuevas denuncias en torno a las afectaciones por los cultivos ilícitos, la explotación ilegal de oro, las fumigaciones con glifosato, el secuestro perpetrado por Los Rastrojos contra una familia Awá en diciembre de 2011, así como la violación de tres mujeres indígenas y el asesinato de uno de sus compañeros ${ }^{60}$;

\footnotetext{
58 Colombia. Corte Constitucional. Sala Especial de Seguimiento. Auto 174 del 9 de agosto de 2011. Magistrado ponente: Luis Ernesto Vargas Silva. Bogotá D.C. (9 de agosto de 2011).

59 El Espectador, Redacción Política, La batalla del Pueblo Awá (22 de marzo de 2012). El Espectador, Redacción Política, La batalla del Pueblo Awá (22 de marzo de 2012).

60 Verdad Abierta, Las voces awá en la Comisión Interamericana de Derechos Humanos (22 de
} 
pues como se enunció más arriba, el terror perpetrado contra esta comunidad no ha cesado desde 2009.

Esta instrumentalización subalterna del derecho internacional por el pueblo Awá ha tenido resultados ambivalentes. Todo este proceso ha generado mayor visibilización de los Awá como pueblo en una grave situación y las medidas cautelares han brindado mayor contenido y legitimidad a sus reivindicaciones. Sin embargo, el proceso ha estado marcado también por la falta de voluntad del gobierno nacional para generar soluciones de raíz a las problemáticas indígenas, poniendo en práctica más bien algunas acciones que, como ya lo vimos, no van más allá de simples atenuantes. Por ahora, es pertinente repasar la gira por Europa en pro de sus derechos fundamentales.

3. La gira por Europa: transnacionalización de la causa Awá

Con el ánimo de continuar con la visibilización de la problemática y la generación de vínculos más allá de las fronteras nacionales, en la generación de redes transnacionales de defensa, se dio inicio a una gira por Europa a cargo de Francisco Javier Cortés-Guanga, secretario general de la UNIPA, en marzo de 2013. Esta estrategia tuvo la particularidad de darse en términos de lo que Santamaría designa como "lobbying internacional" o "diplomacia indígena", lo que convierte el problema que aqueja a los Awá en un asunto de interés global ${ }^{61}$.

En este sentido, los fines de tal gira fueron: denunciar el exterminio físico y cultural, y la emergencia humanitaria y ambiental que enfrentaba la comunidad, lograr una presión internacional sobre el gobierno colombiano para que al fin cumpliera las sentencias de la Corte Constitucional contenidas en los autos A-004-09 y A-174-11, es decir, para el cumplimiento del Plan de Salvamento Étnico y el Plan de Prevención, Urgencia, Reac-

marzo de 2012). Disponible en: http://www.verdadabierta.com/masacres-seccion/3950-lasvoces-awa-en-la-comision-interamericana-de-derechos-humanos

61 Ángela del Pilar Santamaría-Chavarro, Redes transnacionales y emergencia de la diplomacia indígena: un estudio transnacional a partir del caso colombiano (Editorial Universidad del Rosario, Bogotá, Colombia, 2008). 
ción y Contingencia del Pueblo Awá; y por último, proponer la conformación de una veeduría internacional que se encargue de un seguimiento a la situación del pueblo Awá en materia de derechos humanos y de deberes del gobierno ${ }^{62}$.

La gira tuvo recorrido por cuatro países: Bélgica, España, Alemania y Suiza. Inició en Barcelona, donde Cortés participó de la semana de lucha la autonomía y los derechos de los pueblos indígenas de Colombia ${ }^{63}$. Durante esta, se realizó una concentración de una veintena de personas frente al consulado colombiano en protesta por la situación de los pueblos indígenas en Colombia y se entregó el Informe sobre el exterminio del pueblo Awá, elaborado con colaboración del Observatorio ADPI, referenciado con anterioridad a lo largo del artículo ${ }^{64}$. De allí, Cortés partió hacia Suiza.

En Ginebra, Cortés hizo lobby, participó en la vigésimo quinta sesión del Consejo de Derechos Humanos de la Organización de las Naciones Unidas, donde también presentó el Informe sobre el exterminio del pueblo Awá. El secretario aprovechó para radicarlo en varios organismos de la ONU, como la Oficina del Relator Especial para Pueblos Indígenas, la Oficina de la Alta Comisionada para los Derechos Humanos (OACDH) y la Unidad de Pueblos Indígenas de la Organización Internacional del Trabajo (OIT), para poner de manifiesto el incumplimiento del Estado colombiano a diferentes acciones legales dictaminadas por la Corte Constitucional de este país, como el Auto A-00409, el A-174-11 o las medidas cautelares de protección otorgadas por la $\mathrm{CIDH}^{65}$. El representante indígena solicitó a la próxima Relatora de Pueblos Indígenas de la ONU, que pusiera como

62 Observatorio por la Autonomía y los Derechos de los Pueblos Indígenas en Colombia, Observatorio ADPI, Se inicia gira internacional de delegado del pueblo indígena Awá binacional de Colombia y Ecuador por diferentes países de Europa (8 de marzo de 2013). Disponible en: http://observatorioadpi.org/content/se-inicia-gira-internacional-de-delegado-del-puebloindigena-awa-binacional-de-colombia-y-ec

63 Ibid.

64 El Espectador, Agencia EFE, Indigenas colombianos denuncian en España violación de sus derechos (26 de marzo de 2014). http://www.elespectador.com/noticias/paz/indigenascolombianos-denuncian-espana-violacion-de-sus-articulo-483093

65 Organización Nacional Indígena de Colombia, ONIC, Pueblo Awá denunció ante la ONU plan de exterminio fisico y cultural en su contra (19 de marzo de 2014). 
prioridad en el inicio de su mandato una visita al territorio indígena Awá en Colombia.

Recopilando, la importancia de la gira del secretario mayor de la UNIPA por Europa tuvo un balance positivo. En primer lugar, porque se dio a conocer más ampliamente en otro continente la existencia del pueblo Awá y su crítica situación. Pero también porque tendría efectos de visibilización nacional, fundamentalmente por el cubrimiento mediático con el que se trató, tuvo como grata consecuencia una motivación para el pueblo, que por medio de Cortés sintió la solidaridad de la comunidad internacional. Lo siguiente es reflejo de esto:

Entonces eso ha sido una incidencia de la gira, que pues todos nuestros escritos, videos y nuestras denuncias a nivel de Colombia no se han quedado aquí, y es por eso que el pueblo Awá con UNIPA ha tenido una visibilización bastante amplia, porque a nosotros de qué nos sirve hablar con la Defensoría del Pueblo, la Procuraduría y otras instituciones de Colombia si eso no da un resultado, y por lo menos a nivel de todas esas denuncias e informes, por lo menos el gobierno se mueve siquiera un poquito a darle la mano al pueblo Awá y si no, no hay salida ${ }^{66}$.

El sentimiento señalado es tan fuerte que incluso se ha pensado en realizar nuevas giras. Él expresa: "la idea es visibilizar el incumplimiento ante la ONU o ante lo que tengamos [que] ir en instancias internacionales para poder exigir que el gobierno cumpla por lo menos, con las salvaguardas y cómo se va a implementar el proceso de víctimas" ${ }^{97}$. Esto se enmarca en el desarrollo de un razonamiento hacia el futuro en el plano internacional del pueblo Awá, del cual también es muestra la solicitud presentada, en el marco de la gira, a Victoria TauliCorpuz, actual relatora de pueblos indígenas de la ONU, para que ponga como prioridad una visita al territorio indígena Awá en Colombia en su agenda ${ }^{68}$.

66 Entrevista a líder Awá, septiembre de 2015.

67 Entrevista a líder Awá, septiembre de 2015.

68 Observatorio por la Autonomía y los Derechos de los Pueblos Indígenas en Colombia, Observatorio ADPI, El Pueblo Awá solicita a la Oficina del Relator de Pueblos Indigenas de la ONU una visita a su territorio (13 de marzo de 2014). 
Es importante señalar que lo antes mencionado se enmarca en al menos tres estrategias de lobbying: primero, el lobby y la presión contra el Estado colombiano, que significa mostrarlo en el exterior como un violador de derechos humanos; segundo, el lobby ante otros Estados que se traduce en la intentona de generar nuevas alianzas para impulsar así las redes de defensa transnacional, como las hemos entendido aquí, de la cuestión indígena; por último, el lobby ante organismos supranacionales, como la Unión Europea y la ONU, que se convierte en una forma de incidir en la política internacional ${ }^{69}$.

Con la evaluación de esta gira internacional culmina el recorrido por el valeroso proceso de resistencia y lucha del pueblo indígena Awá aquí planteado. En lo que viene, esbozaremos las conclusiones analíticas y propositivas de esta estrategia, guiadas por los resultados de nuestro análisis.

69 Mónica N. Acosta-García, Aproximación al estudio de redes transnacionales de defensa y prácticas de Derechos Humanos: análisis de la incidencia de la ONIC en la Organización de las Naciones Unidas. El caso del desplazamiento forzado de los Pueblos Indigenas Emberas..., $57-130,71$. 
CONCLUSIONES

Según vimos, debido a factores como la inoperancia de los canales internos, el panorama de internacionalización de la cuestión indígena y la solidaridad internacional, el pueblo indígena Awá asumió como estrategia política hacer de su problemática local un asunto de interés global. En este sentido, los Awá emprendieron un proceso de resistencia y lucha en el plano internacional que se ha desarrollado por medio de la generación de redes transnacionales de defensa y de la instrumentalización subalterna del derecho internacional. El diálogo con representantes del pueblo evidencia una clara intención por internacionalizar su causa y por visibilizar su problemática allende lo nacional.

Este proceso ha consistido en la búsqueda de vínculos y alianzas con organizaciones internacionales y la realización de lobbying en instancias internacionales, con el fin de visibilizar globalmente las múltiples problemáticas que aquejan al pueblo y lograr solidaridad hacia las mismas. Así mismo, se ha hecho un aprovechamiento de los canales del derecho internacional para presionar por la garantía efectiva de sus derechos en el plano nacional, con el fin de alcanzar mayor legitimación en sus reivindicaciones. La convergencia de estas dos estrategias ha tenido como fin una formalización de sus reivindicaciones en el derecho internacional y nacional, que suponga una real solución a sus problemáticas. No obstante, los resultados de esta estrategia para el pueblo, aunque han sido positivos en términos de visibilización, aún no han logrado traducirse en soluciones efectivas para su devastadora problemática.

En primer lugar, el derecho internacional ha sido una herramienta fundamental para el pueblo indígena Awá, que ha contribuido a visibilizar su situación y a llenar de contenido sus reivindicaciones. Empero, como bien lo dice Rajagopal frente al papel del derecho en las luchas populares, la existencia de un marco normativo más plural y con mayor capacidad de oposición - por ejemplo, el Convenio 169 de la OIT o la Declaración Universal de Derechos de los Pueblos Indígenas - no significa 
una garantía plena de éxito de los movimientos sociales, que han incorporado en sus repertorios de acción el derecho interno e internacional ${ }^{70}$. En el caso del pueblo Awá, las medidas de protección dictadas por la CIDH no han adquirido aún materialidad, debido a la doble moral del gobierno colombiano que, a pesar de ratificar la Declaración y el Convenio, ha mostrado desinterés y apatía ante la gravísima situación de los Awá, faltando al derecho internacional y al propio derecho interno.

Por otra parte, la generación de redes de defensa transnacional emprendida por el pueblo Awá ha dejado mayores réditos. Esta estrategia constituye una potente táctica para presionar al gobierno de Colombia en el cumplimiento de los autos A-174 y A-004 dictaminados por la Corte Constitucional. De esta manera, el pueblo Awá ha ampliado su espectro de acción mediante la alianza con ONG internacionales y el lobby hecho en instancias internacionales en la gira por Europa. Estas acciones han servido para lanzar un llamado de auxilio para que la presión sobre el Estado colombiano sea reforzada desde afuera. El poder de las organizaciones internacionales ha hecho de amplificador de la voz del pueblo Awá, la cual por sí misma ha sido desoída.

También es posible concluir que hay una tendencia creciente hacia una apropiación de los discursos internacionales sobre los derechos humanos por parte de los pueblos indígenas, que viéndose sometidos a múltiples violaciones de sus derechos ancestrales ven en ese marco una mampara jurídica útil para reivindicar su protección. El pueblo indígena Awá es un gran exponente en esta nueva dinámica. Sin embargo, como se pudo ver, los derechos humanos no siempre ofrecen tal protección, pues es imposible un carácter universal en su aplicación, ya que en realidad estos principios son la expresión de una cultura particular, la occidental. Así, la exclusión de la cosmovisión

70 Balakrishnan Rajagopal, Los límites del derecho en la globalización contrahegemónica: la Corte Suprema de la India y la lucha en el valle de Narmada, en El derecho y la globalización desde abajo. Hacia una legalidad cosmopolita, capítulo VIII, 167-196, 168 (Boaventura de Sousa-Santos \& César A. Rodríguez-Garavito, eds., Carlos F. Morales de Setién-Ravina, trad., Universidad Autónoma Metropolitana, UAM, Cuajimalpa, Anthropos, México, Barcelona, 2007). 
indígena de estos discursos impide que haya una tutela integral de sus derechos. Por esto, el pueblo Awá lee tales discursos como un instrumento y no como un fin en sí mismo.

Ahora bien, es preciso plantear que la estrategia política de internacionalizar la problemática Awá mediante la instrumentalización subalterna del derecho internacional y la creación de redes transnacionales de defensa, si bien ha dado frutos $y$ puede seguir dándolos, es insuficiente si no se articula con otras estrategias de lucha que contribuyan a la superación de sus problemáticas. El proceso organizativo local de los Awá, del que la UNIPA, organización creada en 1990, es la mejor expresión, cuenta con una historia de 25 años de resistencia y lucha que debe seguir fortaleciéndose y, además, abrirse a otros repertorios de acción pensados desde y para lo local, que ejerzan presión para la repercusión fáctica de las resoluciones logradas en el plano internacional o, en otras palabras, la concreción de los esfuerzos internacionales en las realidades locales. 


\section{BIBLIOGRAFÍA}

\section{Libros}

Barrios-Giraldo, Pablo Daniel \& Zapata-Cardona, Carlos Andrés, Declaración de las Naciones Unidas sobre los Derechos de los Pueblos Indigenas: un nuevo reto para Colombia (Centro de Cooperación al Indígena, CECOIN, Organización Indígena de Antioquia, OIA, Bogotá, 2009). Disponible en: http://observatorioetnicocecoin.org.co/cecoin/files/Cartilla.pdf

Galvis-Patiño, María Clara \& Ramírez-Rincón, Ángela María, Manual para defender los derechos de los pueblos indígenas (Due Process of Law Foundation, DPLF, Washington D.C., 2012). Disponible en: http://www.dplf.org/sites/ default/files/manual_de_pueblos_indigenas.pdf

Jaramillo-Jaramillo, Efraín, Tragedia del pueblo indígena Awa, en Los indígenas colombianos y el Estado: desafíos ideológicos y políticos de la multiculturalidad, 188-194 (International Work Group for Indigenous Affairs, Grupo Internacional de Trabajo sobre Asuntos Indígenas, IWGIA, Bogotá, 2011). Disponible en: http://www.iwgia.org/iwgia_files_publications_files/0558_libro_los_indigenas_y_el_estado_2011_COMPLETO.pdf

Keck, Margaret E. \& Sikkink, Kathryn, Activistas sin fronteras: redes de defensa en política internacional (Siglo XXI Editores, Ciudad de México, 2000).

Peñaranda-Supelano, Daniel Ricardo, Organizaciones indígenas y participación política en Colombia. El acceso a los espacios de representación 1990-2002 (La Carreta Editores, Instituto de Estudios Políticos y Relaciones Internacionales, IEPRI, Universidad Nacional de Colombia, Medellín, 2009).

Pizarro-Leongómez, Eduardo, Una lectura múltiple y pluralista de la historia (Comisión Histórica del Conflicto y sus Víctimas, Ediciones Desde Abajo, Colombia, Bogotá, 2015). Disponible en: http://www.altocomisionadoparalapaz.gov.co/ mesadeconversaciones/PDF/Informe $\% 20$ Comisi_n $\% 20 \mathrm{Hist} \_r i c a \% 20 \mathrm{del} \% 20$ Conflicto $\% 20 \mathrm{y} \% 20$ sus $\% 20$ V_ctimas. $\% 20 \mathrm{La} \% 20 \mathrm{Habana} \% 2 \mathrm{C} \% 20$ Febrero $\% 20$ de $\% 202015$.pdf

Rajagopal, Balakrishnan, El derecho internacional desde abajo. El desarrollo, los movimientos sociales y la resistencia del Tercer Mundo (Instituto Latinoamericano de Servicios Legales Alternativos, ILSA, Bogotá, 2005).

Santamaría-Chavarro, Ángela del Pilar, Redes transnacionales y emergencia de la diplomacia indígena: un estudio transnacional a partir del caso colombiano (Editorial Universidad del Rosario, Bogotá, Colombia, 2008).

Sousa-Santos, Boaventura de, La globalización del derecho. Los nuevos caminos de la regulación y emancipación (Instituto Latinoamericano de Servicios Legales Alternativos, ILSA, Bogotá, 1998).

Sousa-Santos, Boaventura de \& Rodríguez-Garavito, César A. (eds.), El derecho y la globalización desde abajo. Hacia una legalidad cosmopolita (Boaventura de Sousa-Santos \& César A. Rodríguez-Garavito, eds., Carlos F. Morales de Setién-Ravina, trad., Universidad Autónoma Metropolitana, UAM, 
Cuajimalpa, Anthropos, México, Barcelona, 2007). Disponible en: http:// www.boaventuradesousasantos.pt/media/El $\% 20$ derecho $\% 20 y \% 201$ a $\% 20$ globalizaci $\%$ C3\%B3n $\% 20$ desde $\% 20$ abajo_Anthropos.pdf

Tarrow, Sidney, The New Transnational Activism (Cambridge University Press, Cambridge, 2005).

\section{Colaboración en obras colectivas}

Acosta-García, Mónica N., Aproximación al estudio de redes transnacionales de defensa y prácticas de Derechos Humanos: análisis de la incidencia de la ONIC en la Organización de las Naciones Unidas. El caso del desplazamiento forzado de los Pueblos Indigenas Emberas, en Identidades políticas porosas: estudios sobre las reivindicaciones nacionales y transnacionales, 57-130 (Ana Rodríguez, Ángela del Pilar Santamaría, Édgar Naranjo, Mónica Acosta \& Pedro Rojas, Editorial Universidad del Rosario, Bogotá, 2012).

Brysk, Alison, Globalización y pueblos indígenas: el rol de la sociedad civil internacional en el siglo XXI, en Pueblos indígenas y politica en América Latina: el reconocimiento de sus derechos y el impacto de sus demandas a inicios del siglo $X X, 17-30$ (Salvador Martí i Puig, coord., Fundación CIDOB, Barcelona, 2007). Disponible en: http://www.cidob.org/es/publicaciones/serie_de_publicacion/ interrogar_la_actualidad/pueblos_indigenas_y_politica_en_america_latina

Rajagopal, Balakrishnan, Los límites del derecho en la globalización contrahegemónica: la Corte Suprema de la India y la lucha en el valle de Narmada, en El derecho y la globalización desde abajo. Hacia una legalidad cosmopolita, capítulo VIII, 167-196 (Boaventura de Sousa-Santos \& César A. Rodríguez-Garavito, eds., Carlos F. Morales de Setién-Ravina, trad., Universidad Autónoma Metropolitana, UAM, Cuajimalpa, Anthropos, México, Barcelona, 2007). Disponible en: http://www.boaventuradesousasantos.pt/media/El $\% 20 \mathrm{derecho} \% 20 \mathrm{y} \% 20$ la $\% 20$ globalizaci $\% \mathrm{C3} \% \mathrm{~B} 3 \mathrm{n} \% 20 \mathrm{desde} \% 20$ abajo_Anthropos.pdf

Sousa-Santos, Boaventura de \& Rodríguez-Garavito, César A., El derecho, la política y lo subalterno en la globalización contrahegemónica, en El derecho y la globalización desde abajo. Hacia una legalidad cosmopolita, capítulo I, 7-28 (Boaventura de Sousa-Santos \& César A. Rodríguez-Garavito, eds., Carlos F. Morales de Setién-Ravina, trad., Universidad Autónoma Metropolitana, UAM, Cuajimalpa, Anthropos, México, Barcelona, 2007). Disponible en: http://www.boaventuradesousasantos.pt/media/El $\% 20$ derecho $\% 20 \mathrm{y} \% 201 \mathrm{a} \% 20$ globalizaci $\%$ C3\%B3n $\% 20$ desde $\% 20$ abajo_Anthropos.pdf

\section{Informes}

Amnistía Internacional, La lucha por la supervivencia y la dignidad. Abusos contra los derechos humanos de los pueblos indígenas en Colombia (Editorial de Amnistía Internacional, EDAI, Madrid, 2010). Disponible en: http://amnistiainternacional. org/publicaciones/97-colombia-la-lucha-por-la-supervivencia-y-la-dignidad- 
abusos-contra-los-derechos-humanos-de-los-pueblos-indigenas.html

Comisión Interamericana de Derechos Humanos, CIDH, Informe Anual 2011, Capítulo III, El sistema de peticiones y casos individuales (Comisión Interamericana de Derechos Humanos, 2011). Disponible en: https://www.oas.org/ es/cidh/docs/anual/2011/Cap3C1.doc

Defensoría Delegada para la Evaluación de Riesgos de la Población Civil como consecuencia del Conflicto Armado, Nota de Seguimiento No. 00109 (Bogotá, 2009). Disponible en: http://sisat.defensoria.org.co/subsitio/ doc/historicoAdvertencia/Notas2009/NS\%20N\%C2\%B0\%20001-09\%20 a $\% 20$ IR $\% 20$ N $\%$ C2\%B0\%20029-07\%20A.I\%20Barbacoas, $\% 20$ Roberto $\% 20$ Pay $\%$ C3\%A1n $\% 20 y \% 20$ Magu $\%$ C3\%AD $\% 20$ Payan-NARI $\%$ C3\%91O.pdf

Fundación Ideas para la Paz, FIP, Dinámicas del conflicto armado en Tumaco y su impacto humanitario (10 de febrero de 2014). Disponible en: http://cdn.ideaspaz. org/media/website/document/52f8ecc452239.pdf

Observatorio por los Derechos y la Supervivencia de los Pueblos Indígenas de Colombia, OPIC, SOS a la ONU y la Corte Penal Internacional sobre el exterminio del pueblo Awá de Colombia (Barcelona, 2012). Disponible en: http:// viva.org.co/cajavirtual/svc0307/pdfs/articulo308_307.pdf

Unidad Indígena del Pueblo Awá, UNIPA; Cabildo Mayor Awá de Ricaurte, CAMAWARI \& Asociación de Cabildos Indígenas del Pueblo Awá del Putumayo, ACIPAP, Actualización plan de salvaguarda étnica del pueblo Awá (Nariño y Putumayo, Colombia, 2012). Disponible en: http://observatorioetnicocecoin. org.co/cecoin/files/P_S $\% 20 \mathrm{Aw} \% \mathrm{C} 3 \% \mathrm{~A} 1 . \mathrm{pdf}$

\section{Tesis}

Franco-Gamboa, Angélica, Reconstrucciones de la cotidianidad en el pueblo indígena Awa: espacios minados, tiempo natural y sobrenatural (Tesis doctoral en Antropología, Universidad Nacional de Colombia, Bogotá, Colombia, 2015). Disponible en: http://www.bdigital.unal.edu.co/49616/

\section{Normatividad internacional}

Organización de Naciones Unidas, ONU, Declaración de las Naciones Unidas sobre los Derechos de los Pueblos Indígenas, 13 de septiembre de 2007. Disponible en: http://www.un.org/esa/socdev/unpfii/documents/DRIPS_es.pdf

Organización de Naciones Unidas, ONU, Pacto de Derechos Civiles y Políticos, 16 de diciembre de 1966. Disponible en: http://www.ohchr.org/SP/ProfessionalInterest/Pages/CCPR.aspx

Organización de Naciones Unidas, ONU, Pacto de Derechos Económicos, Sociales y Culturales, 16 de diciembre de 1966. Disponible en: http://www.ohchr.org/ SP/ProfessionalInterest/Pages/CESCR.aspx

Organización Internacional del Trabajo, OIT, Convenio 107 sobre poblaciones 
indígenas y tribuales, Ginebra, 26 de junio de 1957. Disponible en: http:// www.ilo.org/dyn/normlex/es/f?p=NORMLEXPUB:12100:0::NO::P12100_ ILO_CODE:C107

Organización Internacional del Trabajo, OIT, Convenio 169 sobre Pueblos Indígenas y Tribales en Países Independientes, Ginebra, 27 de junio de 1989. Disponible en: http://www.ilo.org/dyn/normlex/es/f?p=NORMLEXPUB:121 00:0::NO::P12100_INSTRUMENT_ID:312314

\section{Normatividad colombiana}

Colombia, Decreto 1137 de 2010, por el cual el Gobierno Nacional crea la Mesa de Concertación para el Pueblo Awá, 47.679 Diario Oficial, 13 de abril de 2010. Disponible en: https://www.minjusticia.gov.co/portals/0/MJD/docs/ decreto_1137_2010.htm

\section{Jurisprudencia internacional}

Comisión Interamericana de Derechos Humanos, CIDH, Medidas cautelares, MC 61/11, Miembros del pueblo indígena Awá de los departamentos de Nariño y Putumayo, Colombia, 16 de marzo de 2011. Disponible en: http://www.oas. org/es/cidh/decisiones/cautelares.asp

\section{Jurisprudencia colombiana}

Colombia, Corte Constitucional, Sala Segunda de Revisión, Auto A-004-09, 26 de enero de 2009, magistrado ponente Manuel José Cepeda-Espinosa. Disponible en: http://www.corteconstitucional.gov.co/relatoria/autos/2009/a004-09.htm

Colombia, Corte Constitucional, Sala Especial de Seguimiento, Auto A-174-11, 9 de agosto de 2011, magistrado ponente Luis Ernesto Vargas-Silva. Disponible en: http://www.corteconstitucional.gov.co/relatoria/autos/2011/a174-11.htm

Colombia, Corte Constitucional, Sentencia T-025-04, 22 de enero de 2004, magistrado ponente Manuel José Cepeda-Espinosa. Disponible en: http://www. corteconstitucional.gov.co/relatoria/2004/t-025-04.htm

\section{Artículos y notas de prensa}

Colectivo de Abogados José Alvear Restrepo, Colectivo Maloka, Se presentó informe en Barcelona que denuncia el exterminio del pueblo indígena Awá de Colombia. Disponible en: http://www.colectivodeabogados.org/noticias/ noticias-nacionales/Se-presento-informe-en-Barcelona

El Espectador, Agencia EFE, Indígenas colombianos denuncian en España violación de sus derechos (26 de marzo de 2014). http://www.elespectador.com/ 
noticias/paz/indigenas-colombianos-denuncian-espana-violacion-de-susarticulo-483093

El Espectador, Redacción Política, La batalla del Pueblo Awá (22 de marzo de 2012). Disponible en: http://www.elespectador.com/noticias/politica/batalladel-pueblo-awa-articulo-333985

Morris, Hollman (prod.), El pueblo Awá: Aprender y luchar para resistir el engaño [serie de televisión Contravía, capítulo 275] (Morris Producciones, Bogotá, 2012). Disponible en: https://www.youtube.com/watch?v=QwJq-DMysjc

Observatorio de Procesos de Desarme, Desmovilización y Reintegración, ODDR, Universidad Nacional de Colombia \& Fondo de las Naciones Unidas para la Infancia, UNICEF, Caracterización del departamento de Nariño (Universidad Nacional de Colombia \& UNICEF, Bogotá, 2011).

Observatorio por la Autonomía y los Derechos de los Pueblos Indígenas en Colombia, Observatorio ADPI, El Pueblo Awá solicita a la Oficina del Relator de Pueblos Indígenas de la ONU una visita a su territorio (13 de marzo de 2014). Disponible en: http://observatorioadpi.org/content/el-pueblo-awa-solicita-laoficina-del-relator-de-pueblos-indigenas-de-la-onu-una-visita-su-t

Observatorio por la Autonomía y los Derechos de los Pueblos Indígenas en Colombia, Observatorio ADPI, Se inicia gira internacional de delegado del pueblo indígena Awá binacional de Colombia y Ecuador por diferentes países de Europa (8 de marzo de 2013). Disponible en: http://observatorioadpi.org/ content/se-inicia-gira-internacional-de-delegado-del-pueblo-indigena-awabinacional-de-colombia-y-ec

Oficina del Alto Comisionado de Naciones Unidas para los Refugiados, ACNUR, El ACNUR da la bienvenida a la decisión de Colombia de apoyar la Declaración de la ONU sobre los Derechos de los Pueblos Indígenas (24 de abril de 2009). ACNUR. Disponible en: http://www.acnur.org/noticias/noticia/el-acnur-dala-bienvenida-a-la-decision-de-colombia-de-apoyar-la-declaracion-de-la-onusobre-los-derechos-de-los-pueblos-indigenas/

Organización de Estados Americanos, OEA, ¿Qué es la CIDH? (OEA, Washington, 2015). Disponible en: http://www.oas.org/es/cidh/mandato/que.asp

Organización Nacional Indígena de Colombia, ONIC, Pueblo Awá denunció ante la ONU plan de exterminio físico y cultural en su contra (12 de marzo de 2014). https://www.arcoiris.com.co/2014/03/el-pueblo-indigena-awa-denuncia-antela-onu-un-plan-de-exterminio-fisico-y-cultural-en-su-contra/

Revista Semana, Las masacres anunciadas de Nariño (13 de febrero de 2009). Disponible en: http://www.semana.com/nacion/conflicto-armado/articulo/ las-masacres-anunciadas-narino/100085-3

Verdad Abierta, Barbacoas: un olvido, muchos conflictos (13 de mayo de 2015). Disponible en: http://www.verdadabierta.com/victimas-seccion/losresistentes/5777-barbacoas-narino-un-olvido-muchos-conflictos

Verdad Abierta, Las voces awá en la Comisión Interamericana de Derechos Humanos (22 de marzo de 2012). Disponible en: http://www.verdadabierta.com/ masacres-seccion/3950-las-voces-awa-en-la-comision-interamericana-dederechos-humanos 